\title{
ENTRE LA INSURGENCIA Y LAS ENFERMEDADES VENÉREAS: LA ORGANIZACIÓN HOSPITALARIA EN GUADALAJARA, 1811-1823
}

\author{
Hugo Humberto Salas Pelayo* \\ Universidad Michoacana de San Nicolás de Hidalgo
}

\section{INTRODUCCIÓN}

$\mathrm{F}$ sta investigación forma parte de un estudio más amplio Csobre la historia hospitalaria en Guadalajara. ${ }^{1}$ El planteamiento del problema consiste en analizar un fenómeno social enfocado en las enfermedades sexuales y malestares cotidianos (infectocontagiosos y gastrointestinales) que presentó la población asistida en el Hospital Real de San Miguel entre 1811 y 1823 en Guadalajara. Los objetivos del trabajo son: 1) indagar los cambios que a principios del siglo xix se gestaron en la asistencia y función hospitalaria; 2) analizar los criterios que representó la organización terapéutica del espacio hospitalario en la

Fecha de recepción: 1ㅇ de octubre de 2018

Fecha de aceptación: 6 de marzo de 2019

\footnotetext{
* A la memoria de mi padre.

1 Tesis de doctorado en historia por la Universidad Michoacana de San Nicolás de Hidalgo, Morelia, Michoacán. Agradezco los comentarios hechos a este trabajo por Juan Luis Argumaniz Tello y por los dictaminadores anónimos, así como por mis maestros los doctores Javier Dosil, Dení Trejo y Napoleón Guzmán.
} 
distribución de las enfermedades más representativas, como las venéreas; 3 ) descubrir el impacto que causaron los enfermos de sífilis en el Hospital de San Miguel; y 4) analizar la participación y función de los facultativos en las salas del hospital.

El trabajo se basa en la captura y sistematización de los registros hospitalarios consignados en los libros de entradas y salidas de enfermos del Hospital de San Miguel de Belén. ${ }^{2}$ De acuerdo con Oliver:

La fuente nos permite conocer la distribución de los enfermos en el hospital por salas, el número de ingresos diarios, por mes y por año y los periodos de internamiento, entre otras cosas [...] Una característica de este tipo de fuentes, contrario a lo que pudiera pensarse, es que no pueden ser utilizadas para hacer estudios estadísticos sobre enfermedades. La primera sorpresa al analizar los registros de entradas y salidas de enfermos de los hospitales coloniales, para un desconocedor del tema, es que no se anota -salvo algunas excepciones- la enfermedad en el registro de ingreso al hospital. Esto responde a que el hospital en ese periodo es una institución de asistencia más religiosa y social que médica [...] En el caso del Hospital Real de San Miguel es hasta finales del siglo xix, después del triunfo de la medicina clínica en Guadalajara, que en los registros hospitalarios se anota regularmente 'la historia clínica del enfermo' y en ella, obviamente, la enfermedad y el desarrollo de la misma. Sin embargo, como mencionamos antes, excepcionalmente se puede encontrar información relacionada con las enfermedades que permita profundizar en la historia del hospital. Para nuestro caso, cuando se trataba de enfermos de lepra (lazarino), de rabia, de algún problema mental (locos, simples, fatuos, etc.), o de

${ }^{2}$ Libros de "entradas y salidas" del Hospital Real de San Miguel de Belén. $\mathrm{AHJ}, H B, L E S H R S M B$, núm. 33-42. Es importante señalar que algunos libros se encuentran en mal estado, presentan faltantes, fojas mutiladas, con hongos, desprendidas y ubicadas en diferentes libros. Los datos representan aproximaciones y no totales absolutos. 
enfermedades epidémicas (apestados, virolentos, etc.) normalmente se especificaba. ${ }^{3}$

La fuente registra información personal sobre los enfermos que voluntariamente asistían e ingresaban bajo cualquier circunstancia al recinto. ${ }^{4}$ Incluyen la fecha (día, mes, año) de ingreso, salida y muerte ${ }^{5}$ de cada convaleciente, su nombre, el de los padres, si era soltero, o el del cónyuge si era casado o viudo; la calidad, la edad, el estado, el lugar de origen, el nombre de la sala en donde se colocaba al enfermo, número de cama y, durante ciertos periodos, el nombre de la enfermedad.

En el análisis realizado a la fuente se constata que desde fines de 1811 se anota el nombre de la enfermedad de forma regular en cada registro de ingreso del Hospital de San Miguel. Esta razón justifica el inicio de nuestro periodo de estudio y culmina en 1823 porque después de este año los registros que se anotan en los libros de entradas y salidas del hospital son irregulares. Esta circunstancia impide realizar un estudio de largo plazo en los registros de enfermos y en los de mortalidad.

3 Oliver, "Mortalidad y los registros hospitalarios”, p. 458. Lilia Oliver es pionera en los temas de salud y enfermedad en Guadalajara, cuenta con innumerables obras que corroboran esta situación.

4 "Sobre este tipo de registros es importante aclarar que dichos totales no significan el número de personas que fueron hospitalizadas, sino el número de ingresos, es decir, cuando un mismo enfermo tenía varios ingresos al hospital durante ese mismo año, era contabilizado varias veces". Evaluación crítica de los registros hospitalarios, apéndice 5, en Oliver, El Hospital Real, p. 307.

${ }^{5}$ El registro de la "causa de muerte" forma parte de una ponencia que se presentó en el congreso "Las causas de muerte en México del periodo colonial al siglo xx" (El Colegio de Michoacán, Zamora, Mich., mayo 2018) de la Red de Historia Demográfica. El trabajo "Las causas de muerte registradas en el Hospital Real de San Miguel de Belén de Guadalajara, 1811-1823" tiene como base estudiar el registro de defunciones en el hospital durante el periodo 18111823. Se analizan las causas mortis más representativas de los 2864 decesos presentados en el hospital entre 1811-1823, a decir: las fiebres, la diarrea y el mal del galio. 
Durante el periodo de estudio que se propone (1811-1823), la consigna del nombre de la enfermedad y del nombre de la sala están casi completos y resultan trascendentales para los fines del presente trabajo. El cruce de estas variables explica los criterios que rigen la organización terapéutica y el funcionamiento del espacio hospitalario de San Miguel. Pese a que el estudio de este fenómeno solo se puede abordar durante cierto periodo en donde la fuente registra la sala y la enfermedad, específicamente desde noviembre de 1811 hasta finales de 1823 , año en que deja de anotarse el nombre de la sala, representa un instrumento de análisis que, desde el interior del propio hospital, explica el funcionamiento que presenta la institución hospitalaria a fines de la época colonial.

Diversos estudios abordan la historia del Hospital de San Miguel, ${ }^{6}$ los problemas de salud-enfermedad ${ }^{7}$ y el desarrollo de la medicina en Guadalajara. ${ }^{8}$ Sin embargo, con el respaldo de nuevas herramientas de trabajo, fuentes documentales, metodologías y análisis más completos, se ha revalorizado la forma de acercarse al pasado. Desde una óptica interdisciplinaria y replanteamiento de categorías de análisis científicas, han propuesto el estudio de los problemas históricos con mejores fundamentos. Destaca el desarrollo del conocimiento médico y el diálogo con la historia de la ciencia en el contexto social, cultural, político y epidemiológico de los siglos XVIII y XIx.

Los estudios locales no han permanecido ajenos a estas propuestas, han revalorizado la forma de hacer historia y lo han hecho desde diversos ámbitos de trabajo: abordan la fundación e historia del Hospital de San Miguel, la de su manicomio, la de su panteón, definen el concepto cristiano de caridad y de ejercicio

${ }^{6}$ Muriel, Hospitales; Oliver, El Hospital Real; Gálvez, La conciencia regional; Ramos, El manicomio del Hospital Real; Méndez, El núcleo médico funerario; SALAS, "El funcionamiento y la dinámica interna".

7 Argumaniz, "Las epidemias y las medidas".

8 Oliver, Salud, desarrollo urbano. 
espiritual que rigió al recinto a lo largo de la época colonial, analizan la mortalidad hospitalaria durante los momentos de ciertas epidemias, ${ }^{9}$ cuestiones propias de las órdenes hospitalarias, principalmente la administración ejercida por los betlemitas y las tareas adjudicadas a los facultativos, estudian la cobertura y área de influencia hospitalaria, así como los cambios paulatinos de medicalización que presenta la institución durante el siglo XIX y su proceso de modernización. Estos trabajos aportan los elementos necesarios para proponer, junto con el respaldo de fuentes documentales inéditas, una línea de estudio aun no explorada en Guadalajara: la organización terapéutica del espacio hospitalario por medio del análisis de sus salas y enfermedades más representativas entre 1811 y 1823.

El uso de los registros hospitalarios representa una alternativa viable para abordar, con mayor precisión y profundidad, un episodio olvidado sobre la historia hospitalaria en Guadalajara a fines de la época colonial. La propuesta de estudio descubre la presencia de un grave problema de salud pública según las normas culturales y prácticas sexuales de los tapatíos de inicios del siglo xIx, puesto que el galio, cuya sintomatología se asocia con malestares infecciosos de transmisión sexual, registró una alta frecuencia. A partir de los resultados vertidos, podemos

9 Oliver hace un llamado para que los estudios de historia demográfica de Guadalajara incorporen al análisis de la mortalidad tapatía, las defunciones que registran los libros de entradas y salidas del Hospital de San Miguel. Esta situación permite reducir el subregistro, ya que los datos de defunción del recinto se suman a las actas parroquiales de entierro, obteniendo así aproximaciones más precisas sobre la mortalidad. Oliver, "La importancia", pp. 47-67. Bajo esta perspectiva, Argumaniz realizó un ejercicio al agregar a las actas de defunción parroquial de los años 1762 y 1763 (momento en que se presentó en Guadalajara una epidemia de viruela y otra de matlazahuatl, respectivamente) los registros de defunción del hospital durante el mismo periodo. Los resultados redujeron el subregistro de mortalidad durante estas dos epidemias y se obtuvieron aproximaciones más certeras del impacto causado por estas enfermedades en la ciudad. Argumaniz, "Las epidemias y las medidas", pp. 105-121. 
identificar una enfermedad de carácter endémico, como fue la sífilis en la población que ingresó en esa década a dicho hospital. Fue padecida por niños, hombres, mujeres y, sobre todo, jóvenes militares españoles, pero causó baja mortalidad. Incidencia que al parecer permaneció en la secrecía, o al menos no se dio a conocer ni se registró en las defunciones como tal para no dimensionar ni dar a conocer un grave problema de salud y de relajamiento en las conductas sexuales de una población católica. Mal venéreo que para el caso de Guadalajara se atribuye principalmente al movimiento de ejércitos que se desplazaron por la ciudad como parte del movimiento insurgente de 1810 y que, ante la gran cantidad de enfermos, las autoridades del Hospital de San Miguel debieron acondicionar los espacios necesarios y exclusivos para su internamiento.

\section{LA CIUDAD: INICIOS DEL SIGLO XIX}

Guadalajara fue el principal centro administrativo del Occidente de la Nueva España y agrupó a los máximos órganos del gobierno político, religioso, cultural y económico. ${ }^{10}$ Diversos estudios han demostrado su crecimiento desde la segunda mitad del siglo XVIII y primeras décadas del XIX. Aunque no es intención regresar a esos planteamientos, ${ }^{11}$ solo se enfatiza que para 1792 se calculaban 24249 habitantes, ${ }^{12} 35000$ en $1810^{13}$ y un aproximado de 40272 para $1823 .{ }^{14}$ A este crecimiento demográfico gestado principalmente por los flujos migratorios del campo a la ciudad, se agregan diversos problemas sociales: presencia

\footnotetext{
10 GÁlvez, La conciencia regional, p. 162.

11 VAn Young, La ciudad y el campo, pp. 285-305; Serrera, Guadalajara ganadera, pp. 36-51; y Argumaniz, “Las epidemias y las medidas”, pp. 251-268.

12 Menéndez, Descripción y censo general, p. 161.

13 Becerra y Solís Matías, La multiplicación de los tapatios, p. 29.

14 Anderson, Guadalajara a la consumación, p. 45.
} 
constante de epidemias, ${ }^{15}$ falta de higiene, hacinamiento de la población, basura en las calles, mal olor, animales muertos, aguas estancadas, contaminación del río San Juan de Dios y consumo de alimentos en condiciones poco higiénicas. ${ }^{16}$

En el Nuevo Hospital de San Miguel ${ }^{17}$ se presentaron los mismos problemas. Una visita ${ }^{18}$ realizada al recinto durante 1814 señaló sus "graves deficiencias": que el médico, cirujano y practicantes no realizaban de manera correcta las consultas a los enfermos, los sirvientes no suministraban regularmente los víveres, los colchones se encontraban sucios, etc. Estas irregularidades existieron en el recinto a inicios del siglo xIX, ya que el movimiento armado de 1810 provocó aumento de soldados y personas que requerían atenciones.

La ciudad y el hospital se convirtieron en centros receptores de tropas militares: realistas, insurgentes y civiles provenientes de

15 Argumaniz, "Las epidemias y las medidas". El autor analiza la presencia de epidemias de viruela $(1762,1780,1797-1798,1815)$, matlazahuatl (1763), años del hambre (1785-1786), sarampión (1804, 1825) y tifo (1814), presentadas en Guadalajara entre 1762-1825. También aborda las condiciones de poca higiene de la ciudad.

16 BPEJ, CM, núm. 14, f. 18 fr.-25 fr. “[Apuntes de algunas] probidencias que [exige] la constitucion de esta ciudad, para que sea una de las mas comodas y [mas] sanas de la America". En este documento de fines de la época colonial, se señalan las condiciones de poca higiene de la ciudad. Oliver también hace mención de este documento para señalar la misma situación. Oliver, Salud, desarrollo urbano, pp. 45-47.

${ }_{17}$ Durante la época colonial Guadalajara contó con dos hospitales: el primero de ellos, el Hospital de la Santa Veracruz (San Juan de Dios) se estableció en 1557. Muriel, Hospitales, t. I, p. 191. El otro recinto y más importante fue el Hospital Real de San Miguel, fundado en 1581. Su primera sede (1581-1590) se ubicó en lo que actualmente es el Palacio Legislativo de la ciudad; su segunda sede (1590-1794) se estableció en el actual Mercado Corona; y su tercera sede (1794) corresponde al actual Hospital Civil Viejo "Fray Antonio Alcalde". Oliver, El Hospital Real, pp. 47-56.

18 AHAG, $O A, H B$, c. 4 , s/n. Expediente que describe la relación que guarda el Hospital de Belén. Contiene la relación del plan de gobierno que se sigue en cuentas, rentas y fincas (marzo de 1814). 
diferentes puntos de la Nueva España. De los 28281 registros de ingresos capturados durante el periodo de estudio, un aproximado de 54\% no eran originarios de Guadalajara. Inmigrantes que arribaron en forma permanente o temporal para mejorar su calidad de vida en una ciudad que ofrecía las condiciones a militares que se instalaron como parte de las huestes del movimiento insurgente de 1810. A continuación se presentan los registros de ingresos de las tropas: ${ }^{19}$

\section{Cuadro 1}

REGISTROS DE INGRESO DE TROPA MILITAR EN EL HOSPITAL DE SAN MIGUEL (1810-1823)

\begin{tabular}{|c|c|c|c|}
\hline$A \tilde{n} o$ & Total & $A \tilde{n} o$ & Total \\
\hline $1810 *$ & 87 & 1817 & 980 \\
\hline 1811 & 1904 & 1818 & 580 \\
\hline 1812 & 1403 & 1819 & 157 \\
\hline 1813 & 1031 & 1820 & 283 \\
\hline 1814 & 583 & 1821 & 669 \\
\hline 1815 & 1642 & 1822 & 1128 \\
\hline 1816 & 1158 & 1823 & 563 \\
\hline \multicolumn{2}{|c|}{ Total } & \multicolumn{2}{|c|}{12168} \\
\hline
\end{tabular}

FuENTE: AHJ, HB, LESHRSMB, núm. 31-42.

* Se contabiliza desde septiembre de 1810.

En este cuadro se incluyen los ingresos de militares registrados en el Hospital de San Miguel desde septiembre de 1810, con la finalidad de dimensionar la presencia que tuvieron las huestes

19 Los regimientos militares están registrados con diversos nombres, abreviaturas y compañías, en ocasiones difíciles de identificar y de ubicar. Algunos de los más reiterativos son: Batallón de Urbanos de Guadalajara, Guadalajara Granaderos, Regimiento de Toluca, Provinciales de Puebla (de Querétaro, de México), Dragones de México, Milicias Nacionales, Artillería de España, Voluntarios, Patriotas (de diferentes regiones), etc. Incluso, aparecen como "desertores" y "bajas" que, por haber sido militares, los incluimos en los conteos nominales de tropa. 
en el recinto desde inicios del movimiento de independencia. Es un hecho que la insurgencia incentivó el fenómeno de inmigración a la ciudad con el arribo de tropas españolas y grupos de insurrectos que desde diversos puntos de Nueva España llegaron a Guadalajara. Entre los centros urbanos más frecuentes que registró la milicia como lugar de origen en su ingreso al hospital, destacan: Guadalajara con 3649 registros, Toluca 816, Puebla 801, Aguascalientes 534, Querétaro 346, Colima 274 y la Ciudad de México $149 .{ }^{20}$ En su conjunto, estos datos alcanzan un aproximado de $63 \%$ de los cerca de 10358 ingresos de militares consignados en el hospital solo en el periodo que nos ocupa, de fines de 1811 a 1823. Sobre la situación que presentó la tropa militar en la ciudad, Olveda señala:

La aglomeración ocasionó problemas relacionados con el alojamiento, puesto que eran pocos los edificios públicos que podían albergar a los insurrectos. Una parte de los hombres de a caballo se acuarteló en los mesones y en casas particulares; los de a pie en el hospicio, en las plazas públicas, en los portales, en los atrios de los templos, en las calles y en las afueras de la ciudad. ${ }^{21}$

Los registros de militares que presentó el hospital entre 1810 y 1823 alcanzaron un estimado cercano a los 12000 ingresos, la mayoría españoles. Situación que sin duda alteró las dinámicas del recinto y la eficacia del servicio. Aunque este fenómeno es más claro durante enero de 1811 (véase la gráfica 1), momento en que aumentan los ingresos con cerca de 900 entradas tan solo en ese mes, de las cuales un aproximado de 303 corresponden a militares de diferentes regimientos. Sobre la situación que presentaron las huestes en la ciudad a inicios de 1811, Olveda señala:

${ }^{20}$ El resto de los lugares de origen que registró la milicia en su ingreso al hospital corresponden, aproximadamente, a un centenar de diversas localidades que, por su amplitud, no consignamos en el presente estudio.

${ }^{21}$ Olveda, De la Insurrección a la Independencia, pp. 136-137. 
Para llegar a Puente de Calderón antes que Calleja, Hidalgo y su tropa salieron de Guadalajara el 14 de enero a mediodía [...] desaprobó que a punto de salir de la ciudad para enfrentar a Calleja, muchos hombres pretextaran estar enfermos o tener negocios urgentes que atender, y otros simple y sencillamente se escondieran, sin otro motivo que el de aprovechar la ausencia de los dirigentes del ejército rebelde para seguir saqueando las casas y los almacenes particulares. Es vista de esto, decretó que todo aquel que no se incorporara a su respectiva sección, sería considerado como desertor y se haría acreedor del castigo señalado en las ordenanzas militares. También prohibió, por indecoroso y nocivo, que las mujeres acompañaran a la hueste. ${ }^{22}$

No se puede comprobar que los 303 militares ingresados al hospital durante enero de 1811 "pretextaran estar enfermos", puesto que el registro aún no indicaba el malestar. Aunque los soldados que sufrían algún padecimiento podían solicitar permiso especial para ausentarse y retornar a su lugar de origen:

Dentro de la estructura del ejército regular novohispano existían dos tipos de servicios: el de la clase de vivos, donde se desempeñaban los elementos aptos para el servicio de las armas, y el de inválidos, que agrupaba a los soldados que por alguna enfermedad o incapacidad física, no podían continuar activos. ${ }^{23}$

Los ingresos que registra el hospital de militares enfermos ascienden durante la cuarta semana de enero de 1811, justo en el contexto en que la ciudad es recuperada por los realistas y Félix María Calleja entra victorioso a Guadalajara, el 21 de enero de 1811: "a partir de ese día, esta capital no volvería a caer en manos de los insurrectos [...] También fue informado [Calleja]

22 Olveda, De la Insurrección a la Independencia, pp. 165-166.

${ }^{23}$ Rojas, Las milicias de Nueva Galicia, p. 192. 
que alrededor de 200 españoles aún se mantenían recluidos en los conventos". ${ }^{24}$

Es un hecho que el arribo de ejércitos dio una fisonomía diferente de las ciudades novohispanas, entre ellas Guadalajara. Contingentes realistas y destacamentos militares que, aun cuando estuvieron conformados al menos desde las últimas décadas del siglo XVIII, ${ }^{25}$ con el inicio de la insurgencia se reagruparon y desplazaron entre diferentes regiones, ciudades y el campo para atender las necesidades de combate. La movilización generó no solo problemas sociales, de alojamiento, abastecimiento, inseguridad e insalubridad, sino la presencia de todo tipo de enfermedades.

El esparcimiento de virus y bacterias es provocado, en gran medida, por el movimiento de población, migración, comercio y desplazamiento de regimientos militares. Rutas terrestres y marítimas que no solo desplazan contingentes y personas, diseminan las enfermedades y sus mortales virus dando cause a las grandes epidemias. Fue el caso de la presencia del tifo en 1814 y la viruela en $1815,{ }^{26}$ que significaron cruentos periodos de sobremortalidad en gran parte del territorio novohispano, a las que se agregan las enfermedades venéreas, las infectocontagiosas, gastrointestinales y otras que generaron graves problemas de salud pública entre la población de Guadalajara y en los grupos sociales que ingresaron al Hospital de San Miguel padeciendo estos y otros males. A continuación se presentan las variaciones entre los ingresos, las salidas y las muertes que registró el recinto a lo largo de la época de estudio y las estadísticas de los enfermos (véanse la gráfica 1 y el cuadro 2).

24 Olveda, De la Insurrección a la Independencia, p. 177.

25 Sobre la formación de los ejércitos realistas durante la época colonial, particularmente desde fines del siglo xviII, consultar RoJAs, Las milicias de Nueva Galicia.

26 Argumaniz, “Las epidemias y las medidas”, pp. 152-167. 


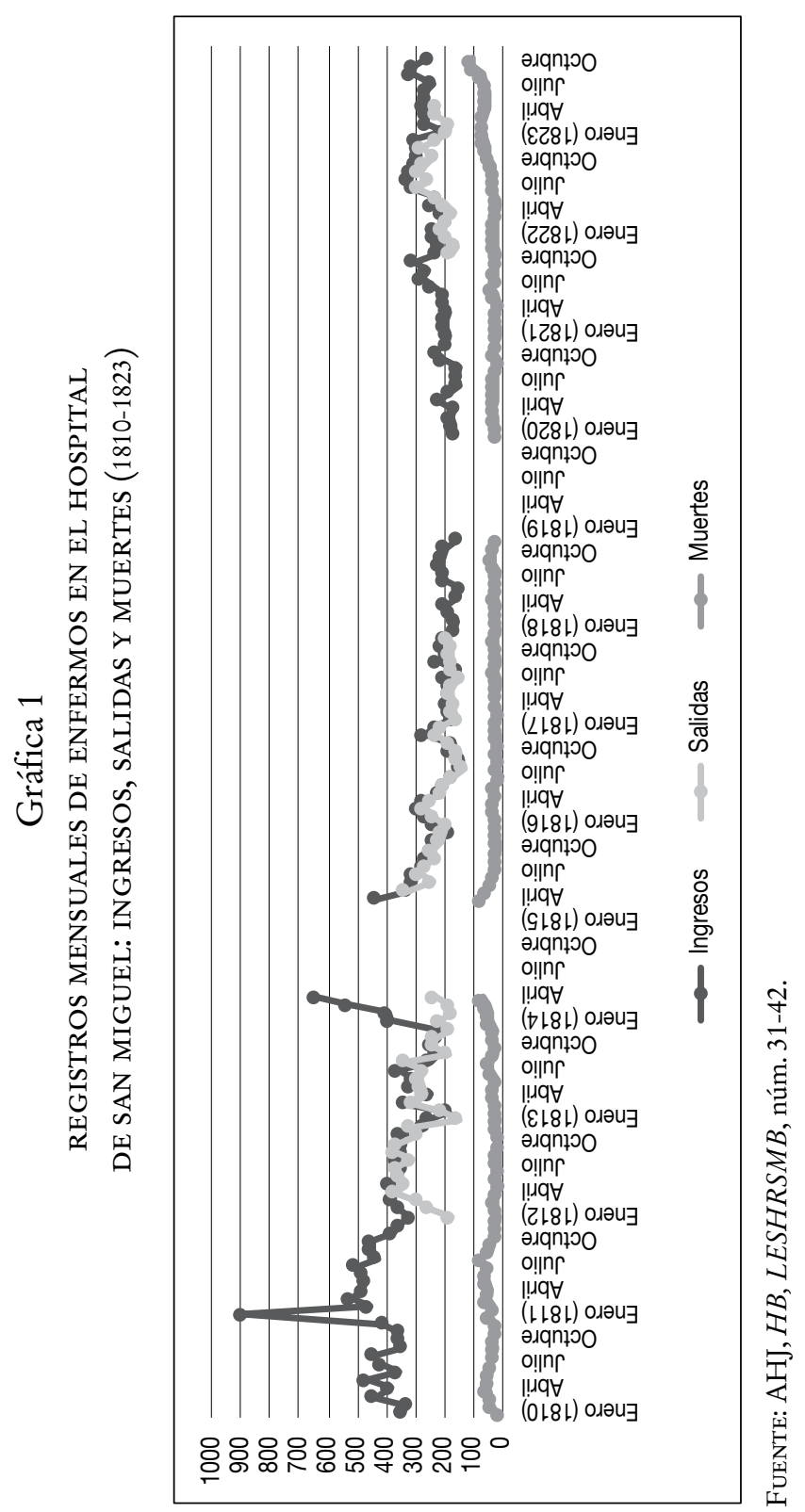




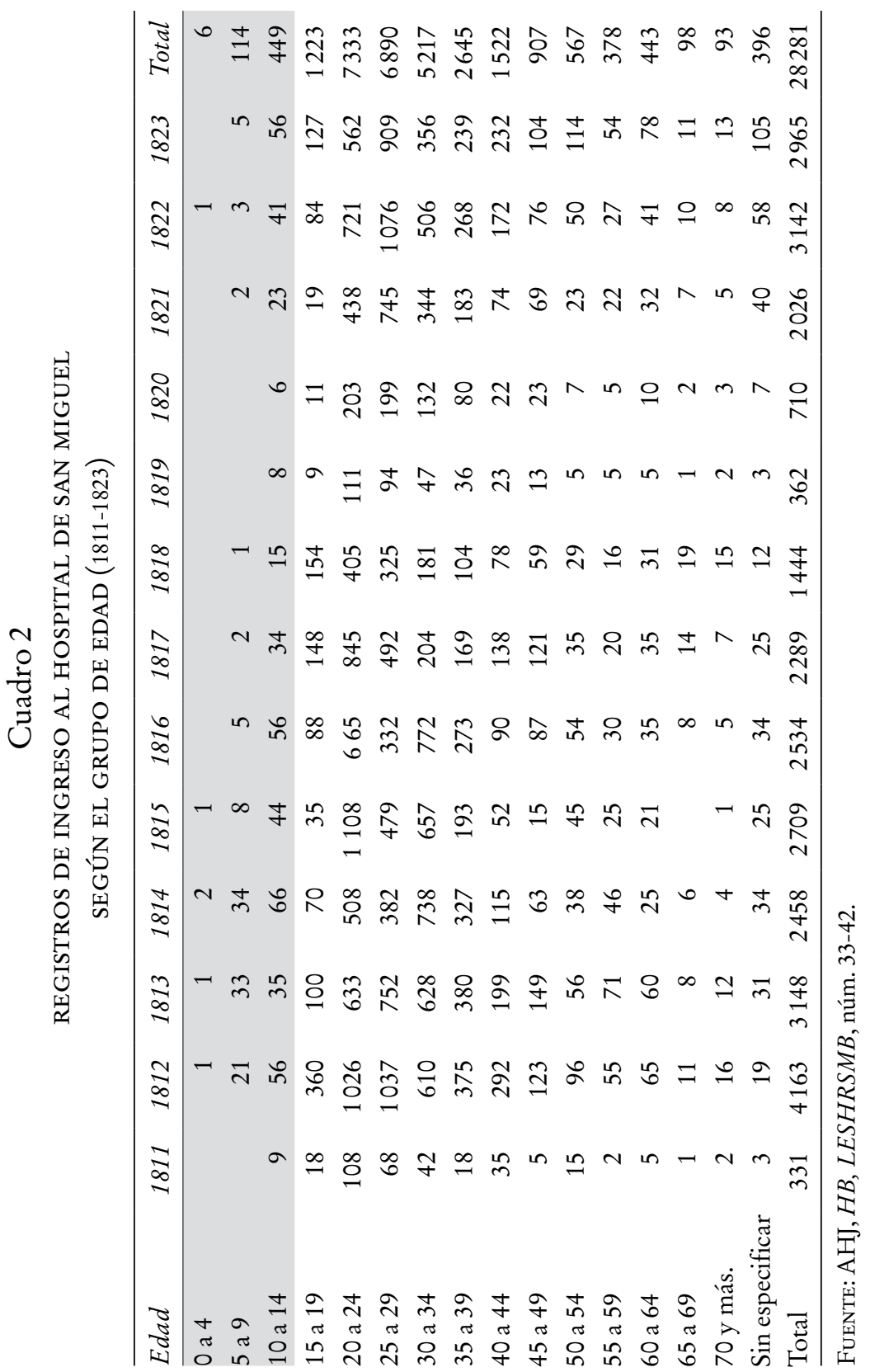


Las cifras mensuales de entradas y salidas que muestra la gráfica 1 mantienen una regularidad en sus series, aunque existen vacíos de información. ${ }^{27}$ Cabe señalar que la capacidad del hospital, la de sus recursos económicos y humanos, deben ser valorados desde un entorno de guerra y epidemias. El hecho de que los ingresos repercutan en la misma estimación con las salidas, nos lleva a plantear algunas reflexiones: en primer lugar, la capacidad del hospital para albergar durante ciertos momentos a determinado número de enfermos, es decir, a mayores ingresos, mayores salidas. Recordemos que este recinto se construyó en 1794 y aun cuando tenía la capacidad suficiente para servir en los momentos de emergencia hospitalaria, la problemática que representó el periodo que nos ocupa rebasó el servicio brindado por la institución. Contexto que se caracterizó por el ingreso desmesurado de militares y civiles al hospital, situación que fue provocada por el movimiento armado de 1810 y por los estragos que causaron la presencia de dos epidemias: tifo de 1814 y viruela de $1815 .{ }^{28}$ Este escenario se manifestó en la ciudad como un grave problema de salud y de muerte; el actuar de las autoridades fue rebasado y las medidas implementadas no lograron reducir las consecuencias mortales de la epidemia, al menos la de tifo de $1814 .{ }^{29}$ En el hospital sucedió lo mismo, el problema se reflejó no solo con los enfermos y espacios que se acondicionaron para su atención, sino con las defunciones registradas a causa de estos periodos de sobremortalidad; en segundo término, el personal que requería el hospital debido al desmesurado ingreso de convalecientes; esta situación demandó ampliación

\footnotetext{
27 Los faltantes que presenta la fuente son los siguientes: en mujeres, de septiembre a diciembre de 1813; en ambos sexos, de junio de 1814 a marzo de 1815 (aunque tenemos los registros de militares de este periodo); en mujeres, faltantes totales entre 1818-1820; en hombres, de abril de 1819 a julio de 1820 ; en hombres, de julio a septiembre de 1821; en hombres, diciembre de 1823.

28 Argumaniz, "Las epidemias y las medidas”, pp. 152-167.

29 Argumaniz, "Las epidemias y las medidas”, pp. 323-330.
} 
de los servicios y de personal. No olvidemos que durante este periodo el hospital era administrado por personal civil a cargo de la Real Audiencia; no contaba con la noble labor ejercida por los betlemitas, religiosos que se caracterizaron por su vocación de atención a los enfermos. ${ }^{30} \mathrm{Y}$, finalmente, poner énfasis en cómo el hospital careció de los recursos económicos suficientes y del personal adecuado que asegura la administración y el servicio hospitalario.

De acuerdo con los datos que arrojan los registros de enfermos, definitivamente todos los convalecientes eran mayores de 15 años (96\%). Situación que manifiesta que el servicio del hospital no estaba destinado para los párvulos o niños. La atención a los menores se efectuaba en otras instituciones: casas de cuna, albergues locales y, principalmente, eran curados y asistidos por sus familiares en casa, lugares en donde recibían mejores atenciones que las proporcionadas por el personal del hospital. En cambio, la población ubicada entre los 15 y 39 años es la que representa el mayor volumen de las estadísticas con $82 \%$ de todos los ingresos. No es fortuito que hombres jóvenes, en su mayoría españoles militares, en edad productiva para trabajar y combatir como parte de las huestes realistas e insurgentes, ingresaran al hospital en búsqueda de alguna ayuda, fenómeno que año tras año se mantiene constante. Si bien, el servicio brindado por el personal del hospital presentó deficiencias y estuvo lejos de curar los malestares cotidianos que aquejaban a la población, en algo debió colaborar para paliar sus enfermedades.

Esta población representa a $78 \%$ de hombres y el resto a mujeres. Aunque los militares, en su mayoría españoles, tienen presencia significativa con $36 \%{ }^{31}$ de todos los registros, y es lo que explica, aunado a la falta de datos durante algunos años

${ }^{30}$ Los religiosos betlemitas administraron el Hospital de San Miguel entre 1704 y 1802. Oliver, El Hospital Real, pp. 120-143.

${ }^{31}$ Este 36\% corresponde a un aproximado de 10358 registros de militares ingresados entre el 23 de noviembre de 1811 y 1823. 
para el caso de la mujer, la gran diferencia numérica entre ambos sexos y con el resto de las calidades. Respecto al tema de la calidad, es necesario mencionar que el contexto de la guerra de insurgencia y la presencia de realistas en la ciudad influye notablemente para que esta categoría se sobredimensione con el caso de los españoles. Este dato deja de registrarse en 1821 y hasta ese año alcanza un estimado cercano a 50\% para los españoles, en comparación con los mestizos e indios que representan 36 y $12 \%$, respectivamente. ${ }^{32}$

\section{LA ORGANIZACIÓN DEL ESPACIO HOSPITALARIO}

El eje de estudio para analizar la organización terapéutica y el funcionamiento que presenta el espacio hospitalario de San Miguel se determina mediante el cruce del nombre de la sala y el nombre de la enfermedad. Los diferentes espacios o salas que conforman la Nueva Fábrica de Belén se visualizan en el plano 1.

El Nuevo Hospital de San Miguel tenía "un total de 22 salas y 20 piezas, separadas por sexo". ${ }^{33}$ De acuerdo con Oliver, la disposición que presentan las salas tiene su origen en los hospitales cruciformes de la Edad Media, ${ }^{34}$ como el antecedente de la planta radiada y como el tipo de arquitectura que a finales del siglo xviII matizó el carácter religioso del hospital, ${ }^{35}$ además de

32 El registro de la calidad deja de anotarse en 1821 con un aproximado de 22174 entradas; hasta este año los datos proporcionan los siguientes ingresos por calidad: españoles 10 861; mestizos 7 978; indios 2641 ; mulatos 275; negros 163 y 256 que no se especifican.

33 Oliver realiza un análisis muy detallado sobre la disposición que presentan las salas del recinto. Oliver, El Hospital Real, pp. 258-268.

${ }^{34}$ Los hospitales cruciformes se caracterizaron por la disposición de sus enfermerías en dos largas crujías, la cual formaba una cruz griega, en donde se colocaba un altar para celebrar los oficios divinos. Oliver, El Hospital Real, p. 238. ${ }^{35}$ El hospital se concebía como "una casa donde se recibía a todos los necesitados. Por lo tanto, en unas ocasiones eran hospitales de pobres, en otras hospederías para peregrinos, bien orfelinatos o asilo para enfermos [...] la 


\section{Plano 1}

\section{PLANO DEL HOSPITAL REAL DE SAN MIGUEL DE BELÉN (1792)}

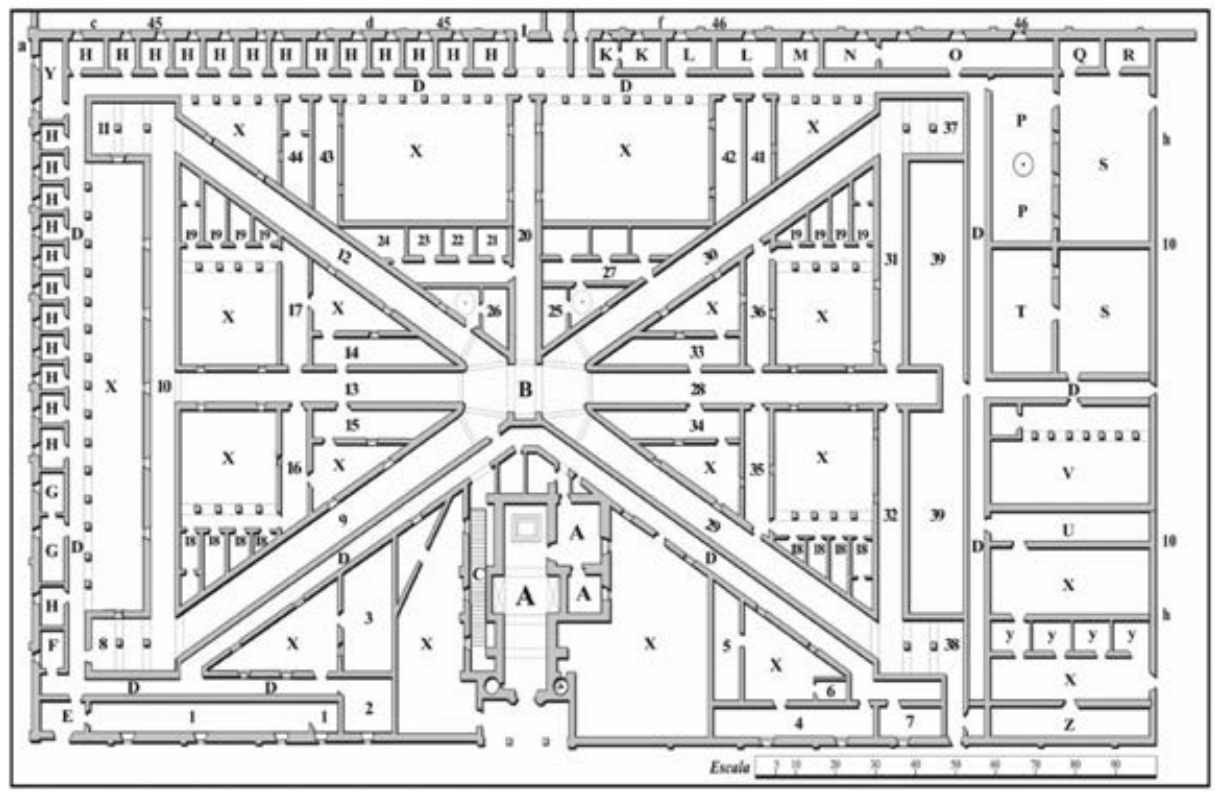

Fuente: AHJ, M, plano 7.7, 518, RF-53 (1792) y Oliver, El Hospital Real, pp. 253-254. Para una mejor visión e interpretación del plano, se delineó solo el conjunto hospitalario, es decir, se omitió la sección del campo santo (núm. 46), el depósito de cadáveres y la capilla (núm. 47), que iban en la parte de arriba. Leyenda del Plano de 1792: "Plano de el Hospital General que el Ilustrísimo Reverendísimo Señor Don Fray Antonio Alcalde, Dignísimo Obispo de Guadalajara, capital de la Nueva Galicia, construyó a sus expensas en esta ciudad y por su Disposición se presenta a S. M. para que le dé el Destino que fuere de su Real agrado: Delineado por el Capitán de el Real Cuerpo de Ingenieros Don Narciso Codina”. Notas. $1^{\mathrm{a}}$. La pared A continuada de 186 varas con la igual b, sobre el lado c.d. de 132 varas forma un rectángulo de 24.552 varas cuadradas, que es la huerta. $2^{\text {a }}$. La pared e.e de 250 varas sobre la f.f. de 204 forma un rectángulo de 51.000 varas cuadradas, que es el campo santo. $3^{a}$. La pared g. de 56 varas, sobre la h.h. de 150 varas forma un rectángulo de 8.400 varas cuadradas, corral de ganado con puerta al campo. $4^{\text {a }}$. Este hospital no tiene piso alto, pero su fábrica está bastante elevada sobre el terreno, bien construida, y cubierta con azotea, con suficientes luces, así por medio de ventanas, como linternas, y claraboyas. Tiene cañerías para dar agua a todas las oficinas necesarias, con su [sic] tarjeas de desagüe. $5^{\text {a }}$. Las camas están de firme de mampostería, arrimadas a lo largo de las salas, y paralelas a sus paredes, y son 775 , con las divisiones, y comodidad posible, y lugar para poner otras. $6^{\text {a }}$. Salas, piezas y oficinas, destinadas para mujeres, están con entera separación. Guadalajara 15 de septiembre de 1792 . 


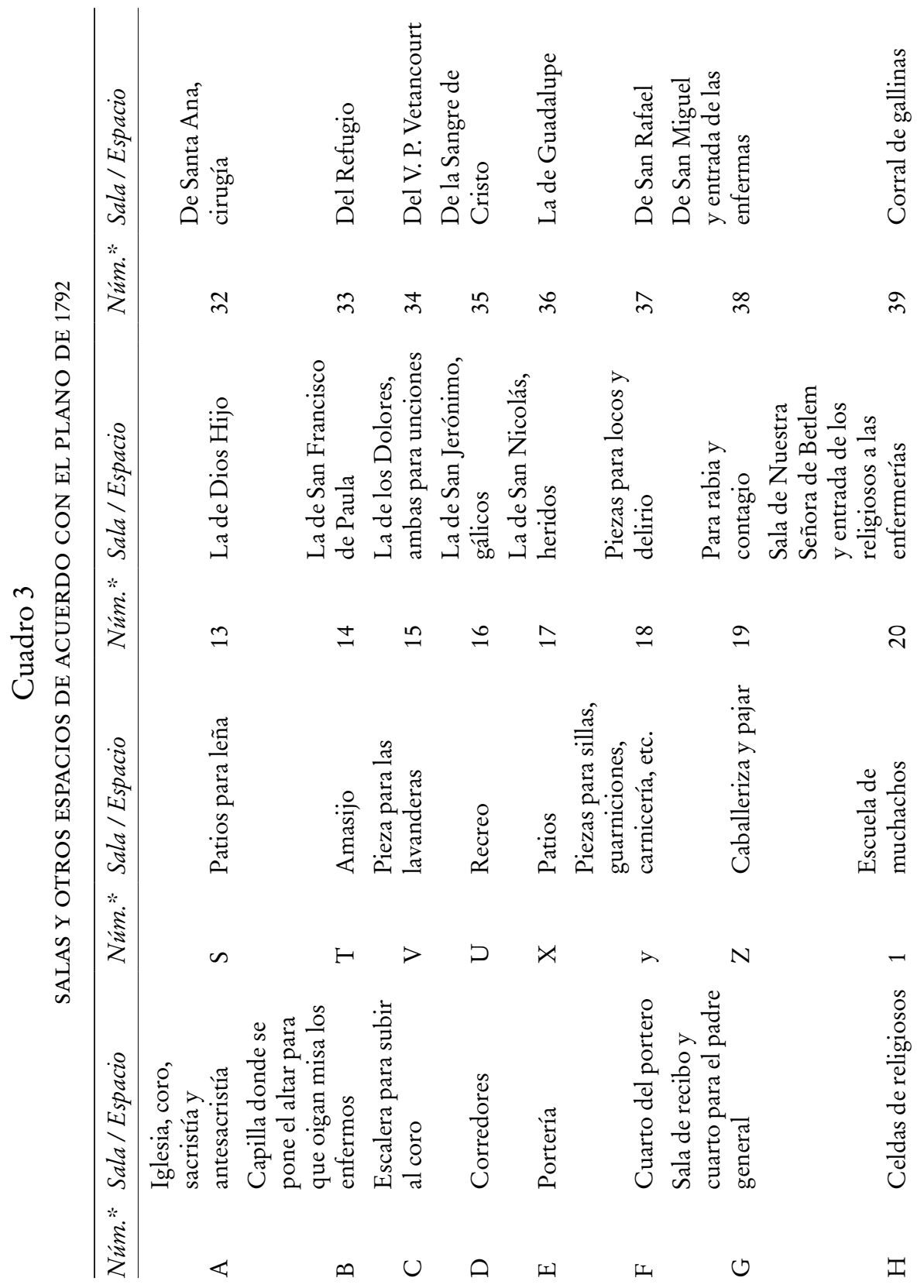




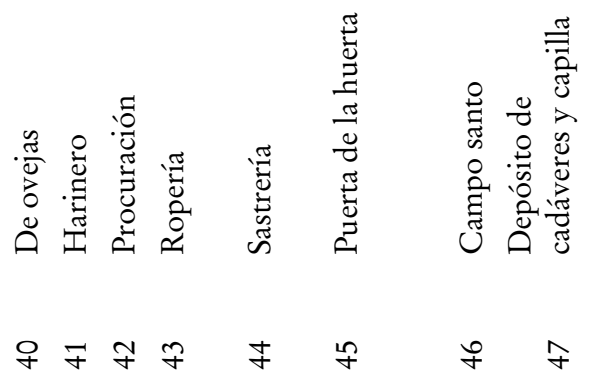

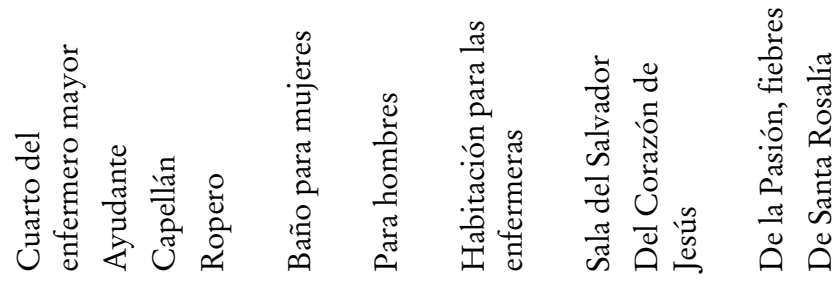
ปที่

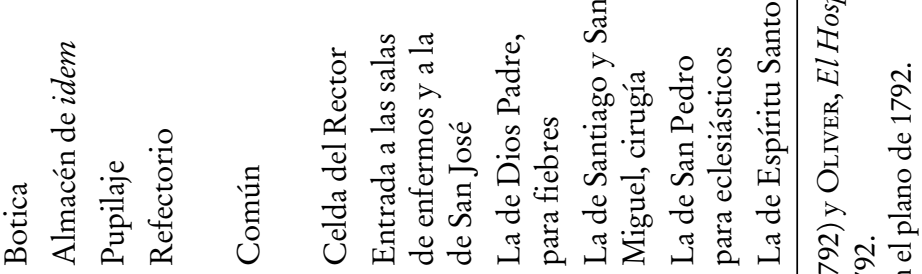

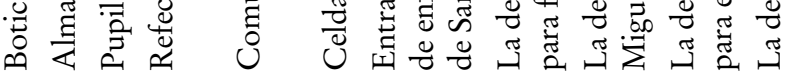

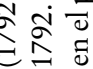

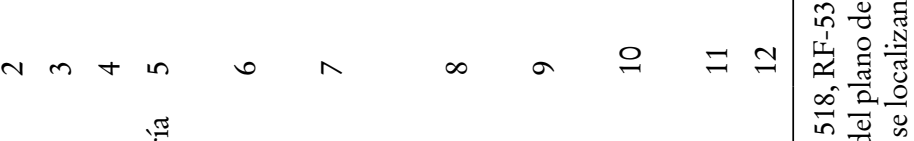

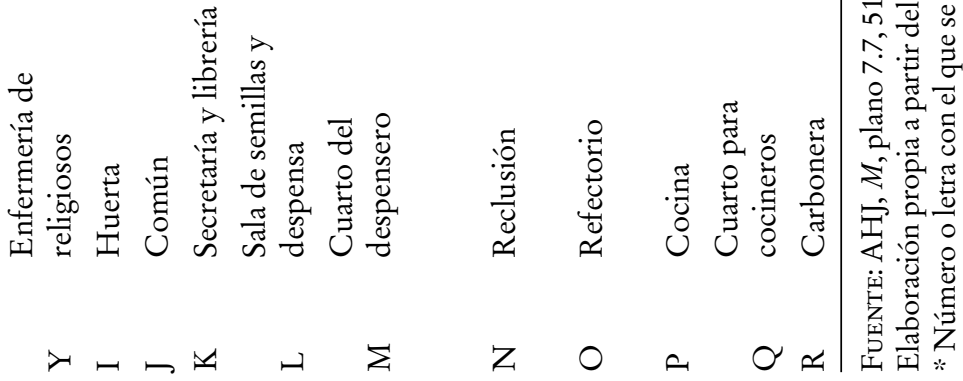


traslucir el ejercicio espiritual que caracterizó a los betlemitas en la asistencia de enfermos. ${ }^{36}$ El recinto tenía "775 [camas...], y lugar para poner otras", ${ }^{37}$ se destinó para asistir diversos padecimientos de la población: enfermos de fiebres, gálicos, heridos, locos y delirio, etc. Incluyó dos escuelas (de escribir y leer), cocina, panadería, habitaciones de religiosos, ropería, baños, botica, patios internos, cementerio y otros espacios no considerados en el plano.

El estudio del espacio terapéutico del hospital se plantea entre el 23 de noviembre de 1811, fecha en que inicia de manera regular el registro de la enfermedad, hasta 1823, año en que deja de anotarse el nombre de las salas. Es necesario señalar que solamente este periodo consigna de manera paralela ambas variables con un aproximado de 28281 ingresos al hospital, mismos que representan los registros nominales capturados. De acuerdo con la consigna que debía hacerse de la enfermedad, la fuente señala lo siguiente:

En esta fecha se le comunicó verbalmente al Comisario de Entradas un Nuevo Método de apuntar los Enfermos por el Señor Regente de esta Real Audiencia, como Comisionado para el arreglo y buen manejo de este Hospital de San Miguel de Guadalajara; y da principio hoy mismo. ${ }^{38}$

caridad lo que pretendía era dar auxilio a todos los necesitados, ya fuesen estos los pobres, los enfermos, los peregrinos que dejaban sus hogares para visitar los grandes santuarios de la cristiandad, o bien los pequeños huérfanos. Ideal era hospedarlos a todos, para que sus distintas necesidades fuesen satisfechas, pero de un modo primordial las necesidades espirituales”. Muriel, Hospitales, t. I, pp. 12-13.

${ }^{36}$ Los religiosos de la Orden de Belén se hicieron cargo de la administración del Hospital de San Miguel (1704-1802) bajo los principios cristianos de la caridad. Oliver, El Hospital Real, pp. 125-143.

37 AHJ, $M$, plano 7.7, 518, RF-53. Plano del Hospital Real de San Miguel de Belén (1792).

38 AHJ, HB, LESHRSMB, núm. 34, f. 25 v. (23 de noviembre de 1811). 
Este método consistió en agregar a los datos del registro el nombre de la enfermedad, aunque es importante señalar que la fuente no suscribe a la persona o empleado del hospital que los anota. A lo largo del siglo xviII fueron asentados y firmados por algún religioso betlemita. Después de la visita de 1792 que la $\mathrm{Au}-$ diencia le realizó a la institución, los frailes dejaron de administrar el recinto en 1802 y salieron del hospital..$^{39}$ Durante este proceso se elaboró, en agosto de 1797, un reglamento en donde se creó un nuevo empleo, el de interventor. Este quedó en manos de Juan de Cancelada y Saavedra y tenía como encomienda asegurar "el buen manejo de las rentas del hospital" ${ }^{40}$ Uno de los puntos del reglamento señaló al encargado de registrar los ingresos:

$15^{\circ}$. El enfermero mayor ha debido llevar siempre un libro de entradas y salidas de enfermos de ambos sexos. Esta misma obligación continuará a su cargo, poniendolo con división a medio margen, para que en la derecha apunte los enfermos, expresando el día de su entrada, calidad, nombre, vecindad, y habitacion; si es casado o soltero; si tiene Padres; si entró por heridas o enfermedad natural; que cama se le dio, que numero tiene, y en que sala se colocó. En el medio margen de la Yzquierda, se anotarán las ropas que traigan con la debida expresión de su clase, y a su tiempo, si murió o sanó, que día fue enterrado o despedido. ${ }^{41}$

A partir de este momento y durante algunos años, los registros del hospital siguieron efectuándose, según lo estipulado en

39 Oliver, El Hospital Real, pp. 133-143.

40 Oliver, El Hospital Real, p. 140.

${ }^{41}$ AMG, S, 7.2 / 1797, Ant. Paq. 14, leg. 47, 13 fojas. Contaduría principal de la Real Hacienda. Instrucción que forman los ministros de la Real Hacienda de la tesorería de la ciudad, en cumplimiento de la orden dada por el intendente de la provincia. Se dictan 36 reglas que debe seguir el interventor coadministrador del Hospital de San Miguel, el cual está a cargo de los betlemitas (24 de agosto de 1797). 
el reglamento, por el fraile "enfermero mayor" y por el mismo Cancelada, como fue el caso del registro de viruela y de otros padecimientos presentados entre 1797-1798, que fueron asentados por ellos mismos. Con los años y de manera progresiva dejó de aparecer la firma del fraile "enfermero mayor" y se registran la de Juan de Cancelada y Bernardo Vilacoba; este último ejercía la función de "Ropero y Comisario de Entradas". Esto se efectuó solo por algún tiempo; durante el transcurso de la primera década del siglo XIX dejaron de asentarse. Cuando menos, durante los años que el presente trabajo plantea, los libros no son firmados por nadie. Aunque de acuerdo con los antecedentes y por lo estipulado en el reglamento, existen dos posibilidades: si se considera el personal que conformó el hospital durante $1814,{ }^{42}$ probablemente el registro lo efectuó algún facultativo que se desempeñó como "enfermero mayor" o "practicante mayor", o estuvo a cargo del "Ropero y Comisario de Entradas".

El término que se anota como enfermedad no necesariamente refleja una certeza y pleno conocimiento en el diagnóstico para asentar el malestar o deceso de la persona. Son saberes que forman parte de los conocimientos tradicionales que permean la concepción de la medicina no solo en Guadalajara, sino en gran parte de las instituciones universitarias y hospitalarias de la Nueva España, entre ellos los facultativos y personal del recinto de San Miguel. Consignan diferentes padecimientos, dolencias y en algunas ocasiones representan síntomas secundarios de los males, desconociéndose la sintomatología exacta que los producen. Un fenómeno que resulta lógico, puesto que los cambios,

\footnotetext{
42 AHAG, $O A, H B$, c. 4, S/N. Expediente que describe la relación que guarda el Hospital de Belén. Contiene la relación del plan de gobierno que se sigue en cuentas, rentas y fincas (marzo de 1814). De acuerdo con esta información que se desprende de una visita realizada a la misma institución en 1814, el Hospital de San Miguel era atendido por un grupo aproximado de 100 empleados, la mayoría civiles. Destaca el considerable número de personal relacionado con el campo de la medicina y la cirugía.
} 
reformas y avances médicos no necesariamente se presentan de forma paralela ni al mismo tiempo entre las instituciones novohispanas. Proceso de largo alcance que debe ser visto en un entorno más amplio y que se manifiesta gradualmente en los saberes tradicionales de la medicina, entre ellos, los registros del Hospital de San Miguel.

Estos datos consignan, en un primer momento, aquellos males que presentan una sintomatología asociada con enfermedades infecciosas de transmisión sexual (los gálicos) y enfermedades infectocontagiosas de las vías respiratorias y gastrointestinales (las fiebres); en segundo grado, se registran diversas formas de lesión o lastimaduras (heridos y contusos); enfermedades de las vías respiratorias (pleuresía); gastrointestinales (diarrea); las referidas al dolor de articulaciones (reumas); de retención de líquidos (hidropesía); por hinchazones e inflamaciones (tumores); de la piel (sarnosos), y en un tercer momento, se registran padecimientos y malestares varios: dolores del cuerpo e internos (cólicos), síntomas de retención y desbordamientos de líquidos naturales (flujo blanco, de sangre); de transtorno mental o alterados de los nervios (dementes, locos y furiosos); enfermos de la piel (lazarinos) y de los órganos (hígado, corazón). A continuación se presentan, de un aproximado de 50 padecimientos consignados de forma regular, las 10 enfermedades más frecuentes (véase el cuadro 4).

Los padecimientos más frecuentes registrados en este cuadro alcanzan $85 \%$ de los 28281 registros nominales capturados. Aunque la presencia de los males es común en todos los grupos sociales, su distribución no es uniforme; en algunos casos el grado de virulencia es más recurrente para determinados sectores. Los malestares presentan una sintomatología asociada por diversas causas, resaltando las generadas por conductas sexuales (gálicos $25.3 \%$ ) y las infectocontagiosas de las vías respiratorias y gastrointestinales (fiebres $24.9 \%$ ). Estos convalecientes se distribuyeron a lo largo de las salas (véanse los cuadros 5 y 6). 


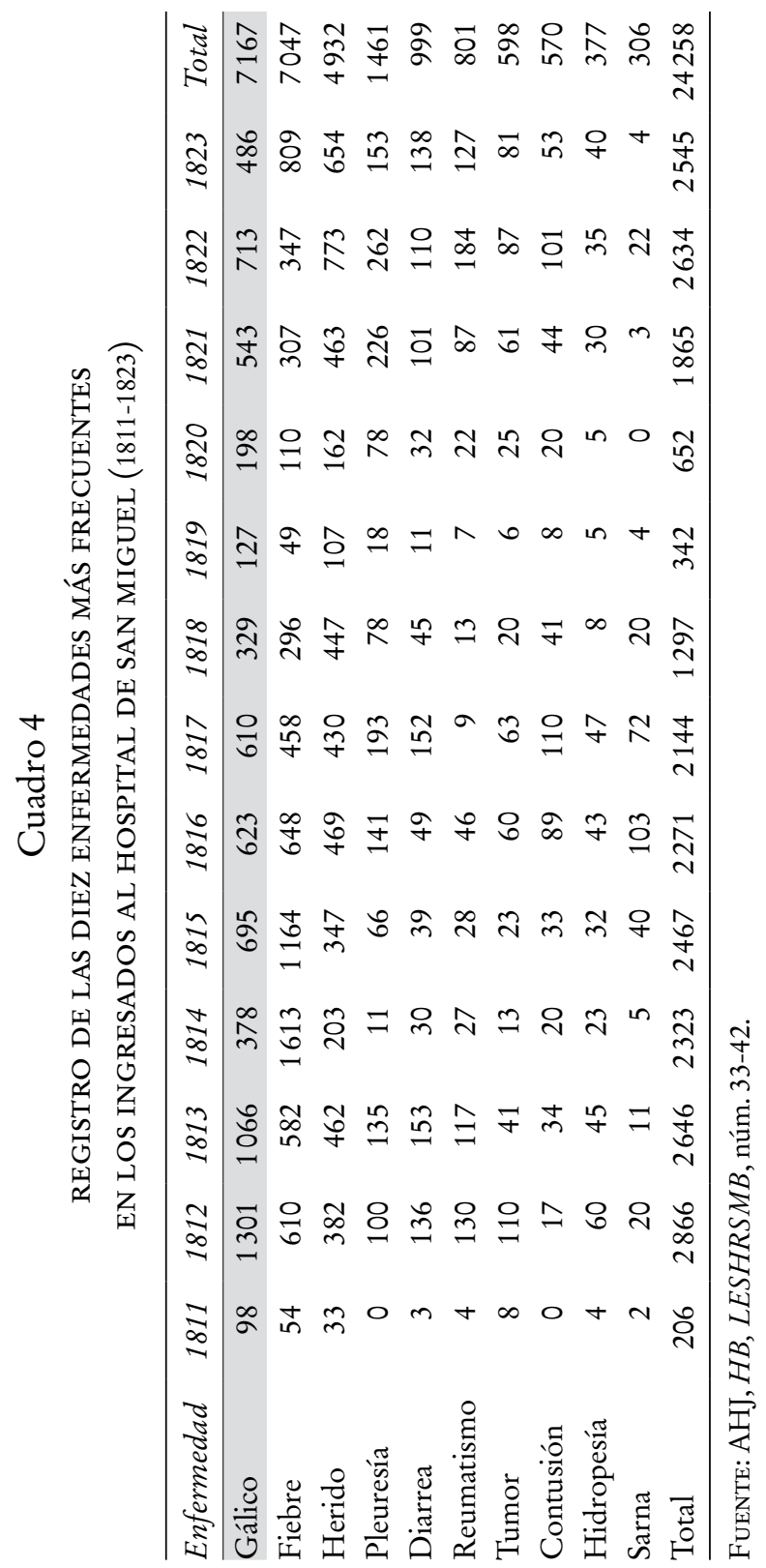




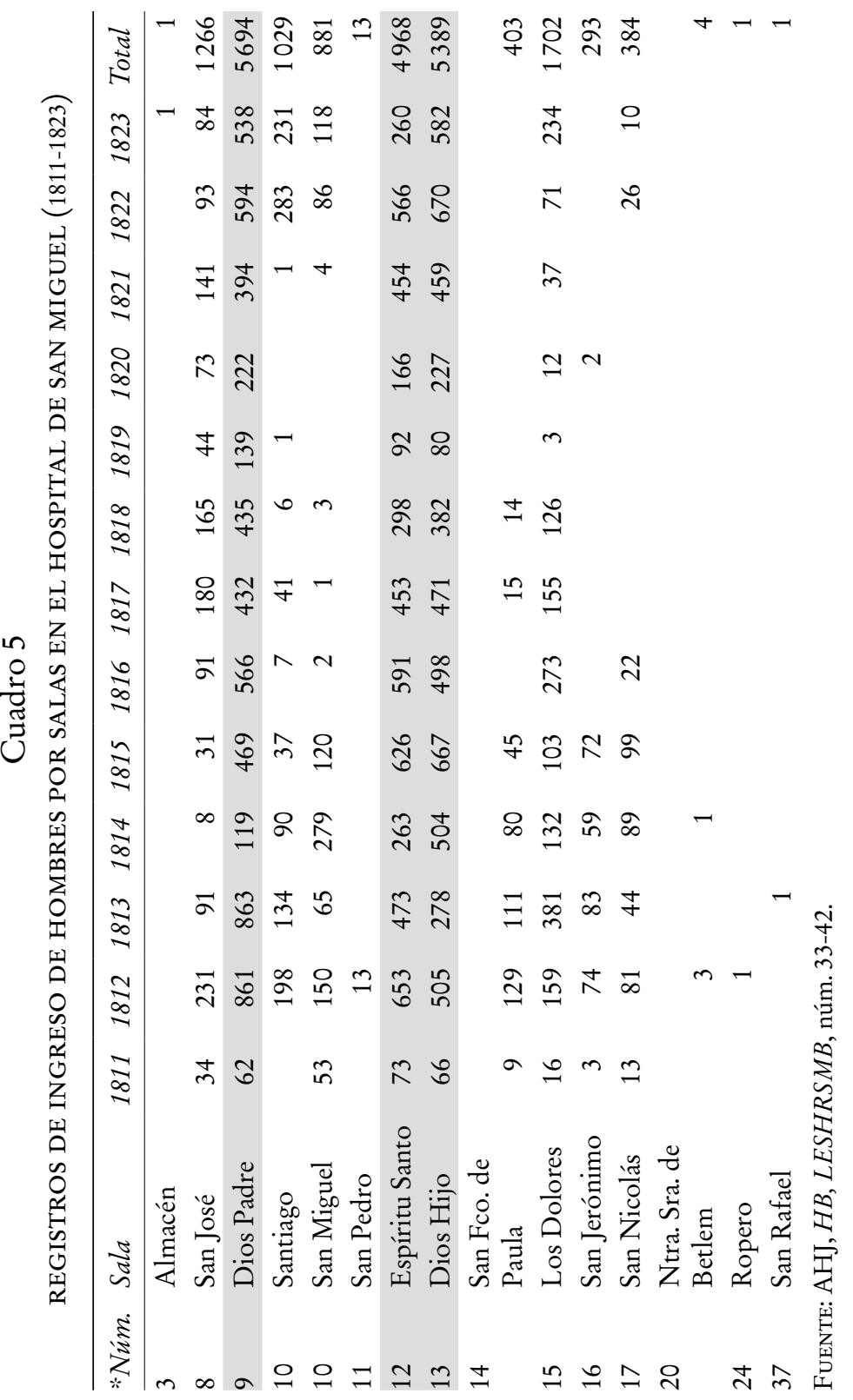




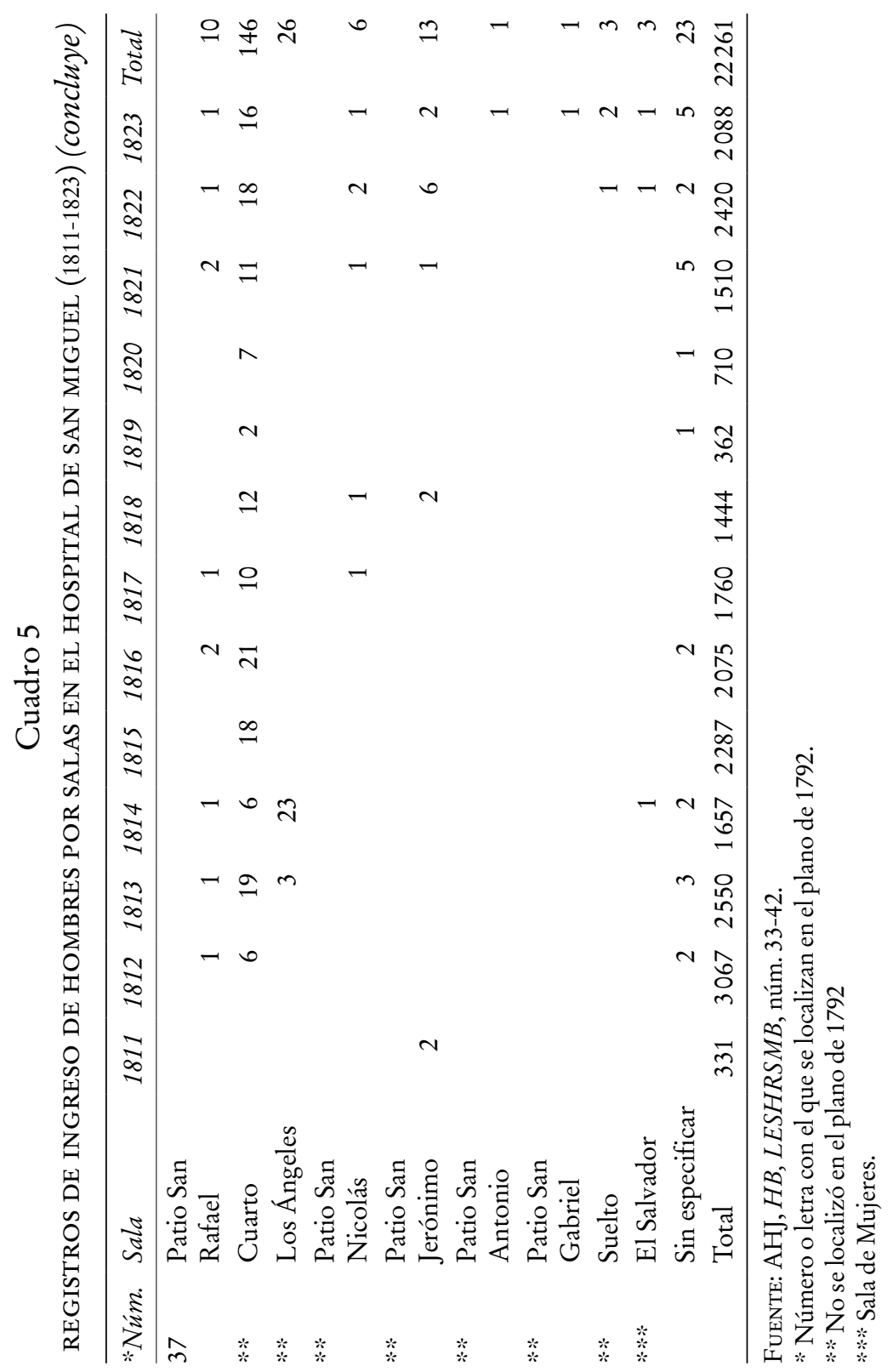




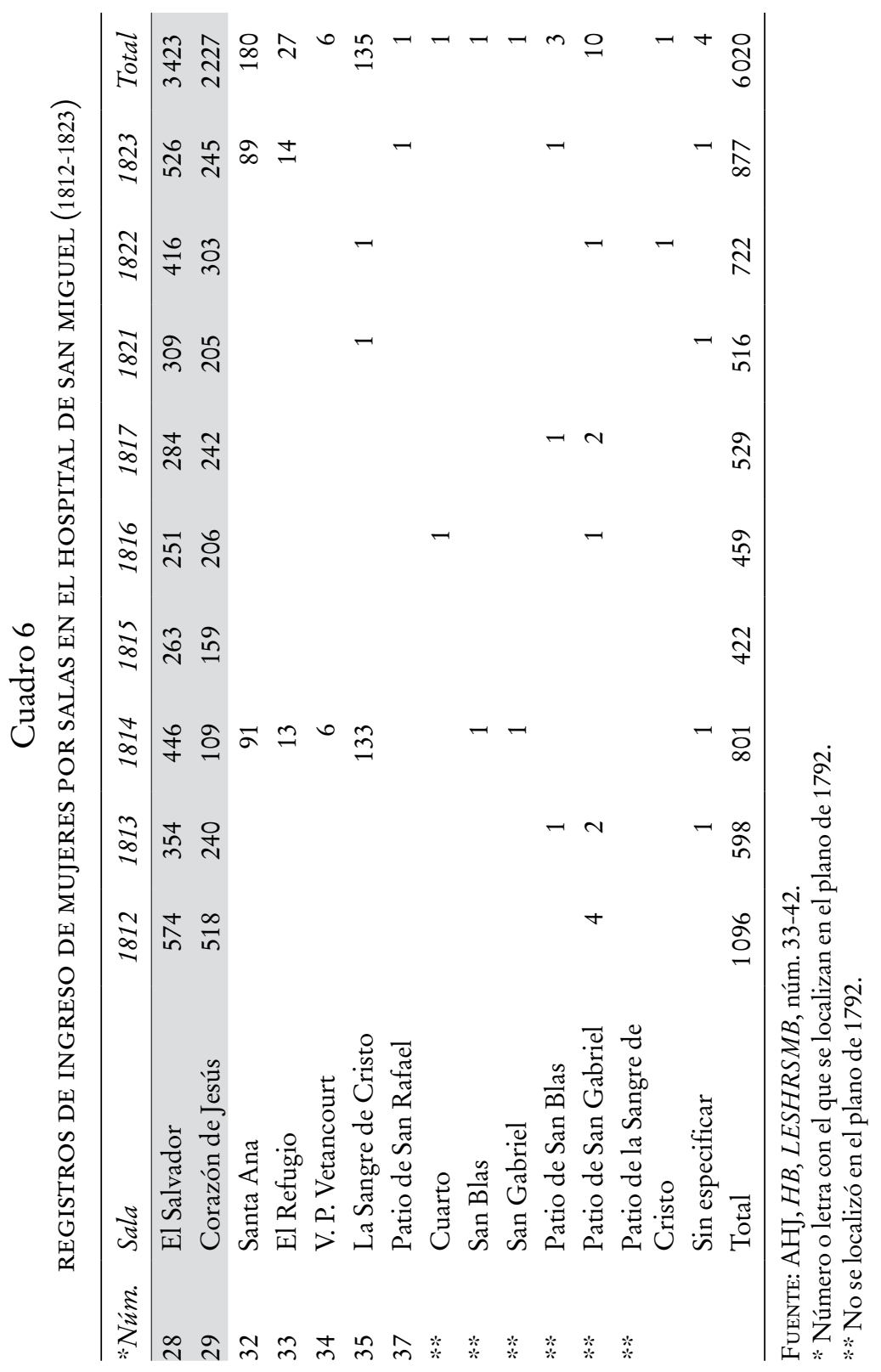


Los datos se presentan año por año para conocer el funcionamiento y las variaciones de cada una de las salas durante la década de estudio. Las que muestran movimiento se adecuan a las necesidades diarias de la población y las dinámicas que presentan mantienen un orden. No es fortuito que ciertas salas registren mayores ingresos que otras, cada una de ellas se destinó para atender ciertas enfermedades, como se estipuló en las ordenanzas que para este momento rigieron, al parecer, el funcionamiento del hospital. ${ }^{43}$

Para el caso de los hombres, que alcanza un aproximado de $78 \%$, demandó mayores áreas para su atención. Se ocuparon todas las que tenían a su disposición, aunque las de mayor capacidad: Espíritu Santo (núm. 12), Dios Hijo (núm. 13) y Dios Padre (núm. 9), fueron las que registraron mayores ingresos.

Para la atención de la mujer que alcanzó poco más de $20 \%$, requirió menores espacios. Dos de sus salas y las de mayor capacidad, El Salvador (núm. 28) y Corazón de Jesús (núm. 29), fueron las que presentaron mayor demanda. Aunque llama la atención que La Pasión (núm. 30), que al igual que éstas, era de las más grandes y con las mismas dimensiones, no registra ni un solo ingreso durante más de diez años.

Estas cinco salas radiadas de mayor capacidad, tanto de hombres como de mujeres, podían albergar un aproximado de 66 camas para enfermos por sala, mientras que el resto lo hacían con cantidades menores. Aunque en tiempos de epidemia y emergencia hospitalaria se acondicionaban todos los espacios internos y rincones disponibles, desde las propias salas, cuartos, piezas, celdas, almacenes, el propio suelo, ventanales y patios en donde se colocaba y asistía a los convalecientes, siempre de forma separada hombres y mujeres.

${ }^{43}$ AMG, S, 7.2 / 1797, Ant. Paq. 14, leg. 47. Instrucción, 13 fojas (24 de agosto de 1797). 
Aun cuando el interés es analizar los criterios que se adoptaron en la distribución de los pacientes con enfermedades venéreas, resulta trascendental problematizar este fenómeno en un marco de estudio más amplio. Son malestares cuya presencia causó impacto mortal en la población, como fue el caso de Europa, y que en los territorios novohispanos no fue la excepción. La sola presencia de estos y otros padecimientos se reflejó con diversos periodos de sobremortalidad, fenómeno que generó el establecimiento de instituciones hospitalarias y espacios exclusivos para atenderlos. Su abordaje histórico es importante para entender el impacto que causaron en el recinto, en la población tapatía y lógicamente su internamiento hospitalario.

\section{LOS ENFERMOS VENÉREOS}

La sífilis ${ }^{44}$ es una infección venérea producida por la espiroqueta Treponema pallidum; normalmente se transmite por contacto sexual y se caracteriza por distintos estadios prolongados en un periodo de años. ${ }^{45}$

${ }^{44}$ El término "sífilis" se registra en los libros de enfermos y salidas del hospital desde inicios de 1830. En el trabajo se usa como sinónimo de gálico y de los diferentes estados evolutivos que presenta esta misma enfermedad.

45 "El primer estadio (sífilis primaria) se caracteriza por la aparición de una pequeña pústula indolora en la piel o en una membrana mucosa, de 10 a 90 días después de la exposición [...] Rápidamente evoluciona a la formación de una úlcera indolora que no sangra y se denomina chancro [...] Cura espontáneamente en un periodo de 10 a 40 días dando la falsa impresión de que el proceso no ha tenido importancia. El segundo estadio (sífilis secundaria) se produce unos dos meses después [...] se caracteriza por malestar general, anorexia, náuseas, fiebre, cefalea, alopecia, dolor óseo o articular [...] La enfermedad sigue siendo muy contagiosa en este estadio y puede contagiarse por el beso. Los síntomas suelen mantenerse durante un periodo de tres semanas a tres meses, pero a veces reaparecen al cabo de los años. El tercer estadio (sífilis terciaria) puede tardar en desarrollarse de 3 a 15 años o más. Se caracteriza por la aparición de tumoraciones blandas [...] La sífilis terciaria puede ser indolora, 
En las primeras manifestaciones aparece el chancro, que es indoloro y desaparece en pocos días. Tiempo después (segunda etapa latente, variable de semanas a meses), los “accidentes" -expresiones de la enfermedad-adquieren importancia por su amplitud en diversas partes del cuerpo, lo cual influye para acudir al médico con cierta alarma y temor. La sífilis terciaria afecta diferentes órganos de forma progresiva, incluyendo el esqueleto (3 a 10 años), de ahí que podamos identificarlo mediante las lesiones sifilíticas. ${ }^{46}$

El desarrollo crónico degenerativo de la enfermedad se presenta de forma intermitente, a través de las diferentes fases que aumentan la letalidad. En el cuerpo humano se manifiesta con pústulas, úlceras indoloras, fiebre, malestares generales y afecciones cutáneas que, de acuerdo con el estadio del malestar, puede pasar inadvertida por la persona que la padece, aunque es evidente que en su fase final provoca "un dolor intensísimo". 47

Es un hecho que las autoridades del hospital, y las de Nueva España en general, desconocieron el cuadro clínico y etiología de esta enfermedad. Los saberes de la medicina clásica ubicaban a la sífilis como una enfermedad correspondiente a la teoría de los humores, tratada por medio del mercurio y de otras pócimas. ${ }^{48}$ No fue sino hasta la década de los cuarenta del siglo xx, con el desarrollo de la penicilina, cuando este mal tuvo curación. ${ }^{49}$

La sífilis surgió en el contexto del Renacimiento en el siglo xv:

El año 1495 fueron sitiadas en Nápoles, por el ejército del Gran Capitán, las tropas francesas que ocupaban la ciudad. Durante el cerco estalló una epidemia extraña y grave: comenzaba la enfermedad

pasando inadvertida [...] en ocasiones, sin embargo, se acompaña de un dolor intensísimo.” GisPert, Diccionario de Medicina, pp. 1163-1164.

${ }^{46}$ Márquez, "La sífilis y su carácter endémico," p. 1138.

47 Gispert, Diccionario de Medicina, p. 1164.

${ }_{48}$ Morales Cosme, El Hospital General de San Andrés, pp. 89-90.

${ }^{49}$ Márquez, “La sífilis y su carácter endémico,” p. 1152. 
con erupciones pustulosas y úlceras, a las que seguían pérdidas de sustancia y la muerte o un estado de miserable invalidez [...] a comienzos del siglo xvi era un azote en toda Europa. ${ }^{50}$

Laín Entralgo y Foucault, contemporáneos del siglo xx y estudiosos de la historia de la medicina, abordan los orígenes de dicha enfermedad. Entralgo la designa como "la gran novedad clínica de los tiempos modernos" ${ }^{\text {1 }}$ y Foucault la denomina como una de las enfermedades venéreas que "de golpe, al terminar el siglo xv, suceden a la lepra como por derecho de herencia”. ${ }^{52}$ Menciona Foucault que pese a que desde su aparición se atendió a los sifilíticos en los hospitales y "muy pronto se ha vuelto cosa médica, y corresponde exclusivamente al médico”, tiempo después perdió el contexto médico en que surgió. ${ }^{53}$

Para el caso de la península española también se convirtió en un serio problema. De acuerdo con Granjel, estudioso de la historia de la medicina en la España del siglo Xviı, los males venéreos, y en particular la sífilis, aparecen mencionados en los textos médicos generales de importantes facultativos del momento. ${ }^{54}$ En el Florilegio medicinal de Esteyneffer (1712) se les describe:

50 Laín Entralgo, Historia de la medicina, p. 311

51 Laín Entralgo, Historia de la medicina, p. 311, citado en Oliver, El Hospital Real, p. 24.

52 Foucault, Historia de la locura, p. 18, citado en Oliver, El Hospital Real, p. 23.

53 Foucault, Historia de la locura, pp. 18-20, citado en Oliver, El Hospital Real, p. 24.

54 “En las obras de Virrey y Mange y Baguer, autor este último que hace descripción en su Floresta de la sífilis, la gonorrea y el bubón venéreo; en la Cirugía natural de Massoneau se ofrece una más puntual referencia a la purgación o gonorrea, los bubones venéreos y la sífilis; los mismos procesos aparecen descritos en las obras de Blas Beaumont [...] Al conocimiento de la sífilis y otras dolencias venéreas hizo contribución valiosa Suárez de Rivera en sus libros Arcanismo antigálico (1721) y Manifiestas demostraciones de las más seguras y suaves curaciones del morbo gálico (1745)." GRANJEL, La medicina española del siglo XVIII, pp. 194-195. 
La definición del morbo galico es difícil, por lo muy vario, como se halla, no tanto en su causa, como en sus efectos; en comun es de malefica, y venenosa qualidad [...] Las señales del Morbo Galico de la primera Especie, son: quando caen los cabellos, o pelos de la barba, o de las sejas sin otra enfermedad. La segunda Especie; quando ay purgacion de materia, que llaman en Gryego Gonorrbea, y suele ser esta materia de mal olor, y de varios colores; también suele aver granos, o manchas coloradas, o amarillas en la cara, o en el cuerpo, los quales no sanan, ni se curan sin que cese la rayz de la enfermedad. La tercera es, quando ay grandes dolores en la Cabeza, y en los Articulos, o Coyunturas asi de dia, y mucho mas de noche; llagas dolorosas en la Garganta, Boca, partes genitales, o en las Ingles, y también se suelen extender, en lo demás del cuerpo. Lo mas grave es, quando el humor llega a roer los mismos huesos, y nervios, con desvelos y calenturillas. ${ }^{55}$

Esto refleja la problemática que para la corona y sus territorios significaron enfermedades como la sífilis, la gonorrea y el bubón venéreo, entre otras. Granjel aborda esta situación y señala que "en la actividad hospitalaria sigue practicándose el clásico tratamiento con 'unciones' de los sifilíticos". ${ }^{56}$

Las enfermedades venéreas representaron un mal que, al igual que varias otras, apareció en el Nuevo Mundo durante el proceso de la conquista. Alberro advierte cómo se realizó este proceso que detonó y agravó su presencia y dispersión entre la población novohispana:

Quizás no resulte inútil recordar que la conquista se realizó bajo el signo de la libertad y del absoluto desenfado propios de este tipo de aventuras [...] bástenos mencionar las trayectorias poco ejemplares de la mayoría de los principales actores de la conquista, tanto

55 EsteynefFer, Florilegio medicinal, p. 298.

56 Granjel, La medicina española del siglo XVIII, p. 195. 
españoles como indígenas, empezando con el mismo Cortés a quien fue preciso recordar la existencia de una primera esposa, en España, cuando éste pretendió contraer segundas nupcias. ${ }^{57}$

Para los territorios novohispanos, la presencia de esta y de otras enfermedades más letales, como la viruela, representaron serios problemas de salud y de muerte por la elevada mortalidad que causaron. Dadas estas condiciones, desde el siglo XVI se impulsó el establecimiento de una serie de recintos destinados para atender todo tipo de padecimientos de las diferentes calidades que conformaban la población novohispana. En la capital virreinal surgieron hospitales para dementes, como San Hipólito y Divino Salvador, para leprosos San Lázaro, y para sifilíticos el Hospital del Amor de Dios (1540), mismo que se incorporó a las instalaciones del Hospital de San Andrés en 1788. ${ }^{58}$ Incluso, para el caso de otros reinos en América, como fue Cuba, un reglamento para el establecimiento de hospitales, fechado en 1776 y expedido por Carlos III, destinó uno de sus apartados para tratar las enfermedades venéreas. En la "Prevención a los facultativos que administran las unciones o panacéa”, se estableció:

Expedir las providencias conducentes (sin embargo de lo que queda explicado en los Artículos dirigidos al Cirujano mayor) para la mejor preparación, allanar quantos obstáculos se presenten, elegir Sala acomodada, y de resguardo, con las camas correspondientes, a fin de proporcionarles todos los medios capaces de producir una feliz curación, y el posible alivio en la carrera penosas del Ptialismo; haciendo, que para la preparación se apronten Bañaderas,

${ }^{57}$ Alberro, "La sexualidad manipulada en Nueva España," pp. 241-242, citado en Oliver, El Hospital Real, p. 88.

${ }^{58}$ Morales Cosme, El Hospital General de San Andrés, pp. 49 y 86. 
Tinas, $u$ otros Vasos equivalentes en que puedan bañarse los que lo necesiten. ${ }^{59}$

Para el caso de la Guadalajara colonial, De la Mota y Escobar señaló que en el Hospital de la Santa Veracruz (San Juan de Dios) "se curan enfermos de llagas y morbogalico". ${ }^{60}$ Incluso, en el mismo San Miguel de Belén desde finales del siglo XVII se recibieron este tipo de enfermos, ${ }^{61}$ y con el establecimiento en 1794 de la "Nueva Fábrica” se destinaron tres salas de mediana capacidad para su tratamiento: San Jerónimo para gálicos y San Francisco de Paula y Los Dolores, para las "unciones.” El hecho de que desde 1794 se hayan destinado tres áreas para su atención manifiesta la grave problemática que representaron las enfermedades venéreas en Guadalajara. Esta situación Oliver la anticipa y señala en su trabajo ${ }^{62}$ y los registros hospitalarios aquí estudiados la constatan.

Este abordaje histórico de la sífilis nos da una perspectiva del gran impacto que significó su presencia no solo en Europa, sino en los territorios novohispanos. No es fortuito que para su atención se hayan destinado ciertos hospitales, lo que constata la gravedad de la enfermedad. Para el caso de Guadalajara, interesa acercarnos a su morbilidad y mortalidad, destacar los diversos nombres con que se consignó y quiénes la portaban: enfermaban niños, hombres, mujeres y, sobre todo, militares españoles que año tras año ingresaban al hospital para recibir asistencia social.

A continuación se presentan los nombres con que se registró este padecimiento en el hospital y estadísticas de los enfermos:

59 Seis impresos relativos al establecimiento, pp. 28-29, citado en OlIVER, El Hospital Real, p. 264.

60 De la Mota, Descripción geográfica, p. 26, citado en Oliver, El Hospital Real, p. 88.

61 Oliver, El Hospital Real, p. 167.

62 Oliver, El Hospital Real, p. 267. 


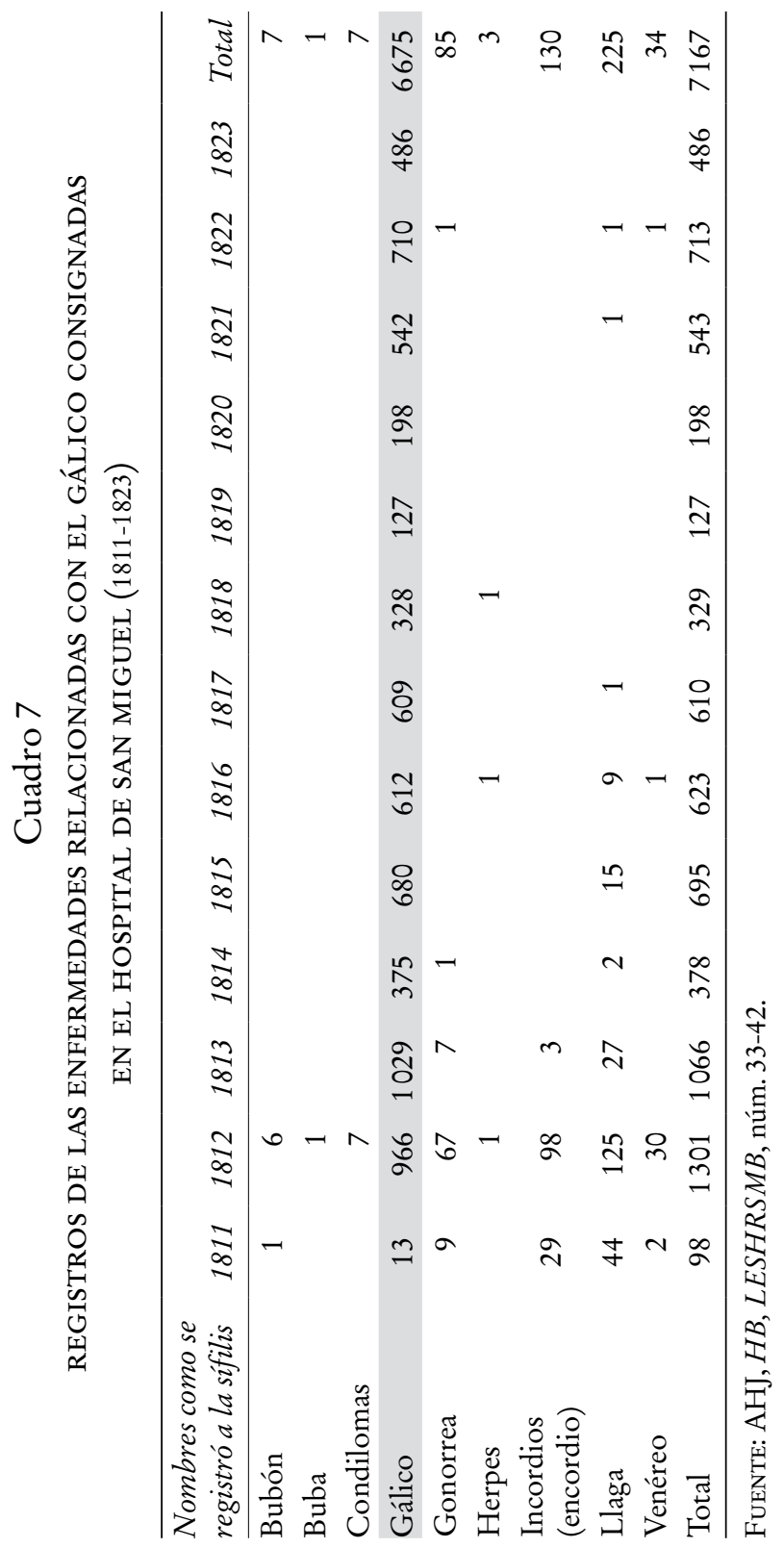




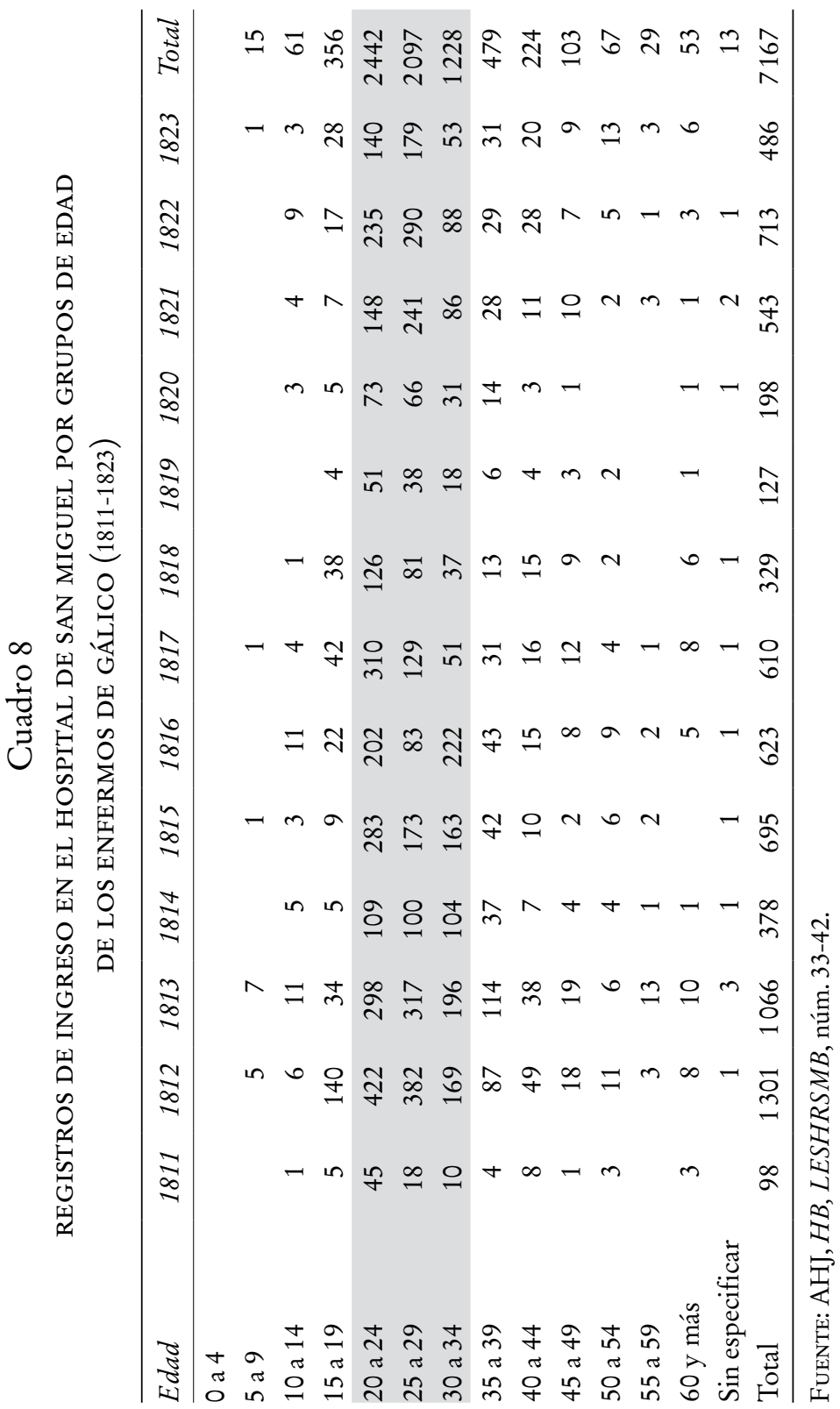


La enfermedad permaneció latente en otras regiones durante el siglo XIx: "la sífilis ya era reconocida en Francia y México como común y de alta frecuencia; su carácter endémico era patente entre los médicos capitalinos" ${ }^{63}$ En el Hospital de San Miguel la enfermedad se consignó de diversas maneras, según criterios de la época se anotaban los síntomas o lesiones visibles del enfermo (una llaga o bubón) y de acuerdo con las diversas maneras en que históricamente se le llamó. Los datos que arrojan los registros del recinto señalan que el mal alcanzó poco más del $25 \%$ de todos los ingresos consignados durante el periodo de estudio. El 1\% corresponde a párvulos menores de 14 años:

[...] los niños adquirían la enfermedad en el vientre de sus madres infectadas, o en el nacimiento, o, bien, por contagio durante el amamantamiento de éstas, no por herencia, ya que no se trasmite vía genética. También por contagio de sus nodrizas y mediante la inoculación de la vacuna antivariólica procedente de niños enfermos sin diagnosticar. ${ }^{64}$

Los registros del Hospital de San Miguel arrojan un promedio de $99 \%$ para los mayores de 15 años, aunque los ubicados entre los 20 y los 34 años representan poco más de tres cuartas partes de la muestra $(80 \%)$, periodo de vida productivo y reproductivo de los jóvenes que la padecieron. Precisamente, son los varones quienes con mayor frecuencia registran algún mal venéreo, alcanzan un aproximado de $84 \%$ de los datos, mientras que el resto corresponde a mujeres. Esto significa que uno de cada cuatro de los enfermos ingresados al recinto, mayoría absoluta de hombres, portaban el mal, lo cual refleja el grave problema de salud que padeció la población y la emergencia hospitalaria que este fenómeno representó para la atención de enfermos.

\footnotetext{
63 Márquez, “La sífilis y su carácter endémico”, p. 1111.

64 Márquez, “La sífilis y su carácter endémico”, p. 1151.
} 
Los datos que consignan los registros hospitalarios suscriben los enfermos que salieron del recinto y los que murieron en su interior. Esta información permite calcular la morbilidad ${ }^{65} \mathrm{y}$ mortalidad ${ }^{66}$ que presentaron los males venéreos en el Hospital de San Miguel.

A partir de los resultados vertidos en los cuadros podemos identificar una enfermedad de carácter endémico, como fue la sífilis, en la población que ingresó en esa década al hospital. De acuerdo con estos datos, la morbilidad que registró el mal gálico presentó alta frecuencia, la más elevada respecto a las enfermedades que consigna la fuente. Alcanzó un promedio general de $25 \%$ respecto a los más de 50 padecimientos que por lo común suscriben los registros del recinto durante el periodo de estudio. Si se considera que el dato corresponde solamente a un malestar, la frecuencia es elevada, aunque al contextualizar la interpretación en el entorno histórico del movimiento de independencia, la presencia de la milicia en la ciudad explica la problemática. ${ }^{67}$ Este grupo social la padeció en un $55 \%$ y, al parecer, la mantuvo en forma endémica, al menos durante el periodo que nos ocupa. No es fortuito que en este mismo entorno el virrey Félix María Calleja reiterara a sus tropas realistas:

65 La morbilidad se entiende como la "frecuencia con la que se produce una enfermedad o anomalía; se calcula dividiendo el número total de personas de un grupo por el número de las afectadas por la enfermedad o anomalía”. Gispert, Diccionario de Medicina, p. 878.

66 La mortalidad se entiende como la cantidad de fallecimientos en tiempo y espacio determinados. Se obtiene de la proporción de enfermos que registraron el mismo mal en el Hospital de San Miguel, en este caso todos los venéreos, y de estos, cuántos murieron en el recinto por la misma causa.

67 Entre los centros urbanos más frecuentes que registraron los militares enfermos de galio como lugar de origen en su ingreso al hospital, destacan: Guadalajara con 1353 registros, Toluca 334, Puebla 332, Aguascalientes 270, Querétaro 139, Colima 112 y la ciudad de México 57. En su conjunto, estos datos alcanzan un aproximado de 65\% de los cerca de 3987 ingresos de militares enfermos de sífilis consignados en el hospital solo en el periodo que nos ocupa, de fines de 1811 a 1823. 
Cuadro 9

REPRESENTACIÓN DE LAS ENFERMEDADES VENÉREAS

REGISTRADAS EN EL HOSPITAL DE SAN MIGUEL (1811-1823)

\begin{tabular}{rcccc}
\hline Año & $\begin{array}{c}\text { Enfermedades diversas } \\
\text { (excepto venéreas) }\end{array}$ & $\begin{array}{c}\text { Enfermos venéreos } \\
\text { (excepto militares) }\end{array}$ & $\begin{array}{c}\text { Militares } \\
\text { venéreos }\end{array}$ & $\begin{array}{r}\text { Total de } \\
\text { ingresos }\end{array}$ \\
\hline 1811 & 233 & 25 & 73 & 331 \\
\hline 1812 & 2862 & 650 & 651 & 4163 \\
1813 & 2082 & 530 & 536 & 3148 \\
\hline 1814 & 2080 & 169 & 209 & 2458 \\
1815 & 2014 & 191 & 504 & 2709 \\
\hline 1816 & 1911 & 237 & 386 & 2534 \\
1817 & 1679 & 252 & 358 & 2289 \\
\hline 1818 & 1115 & 125 & 204 & 1444 \\
1819 & 235 & 47 & 80 & 362 \\
\hline 1820 & 512 & 66 & 132 & 710 \\
1821 & 1483 & 253 & 290 & 2026 \\
\hline 1822 & 2429 & 324 & 389 & 3142 \\
\hline 1823 & 2479 & 311 & 175 & 2965 \\
\hline Total & 21114 & 3180 & 3987 & 28281 \\
\hline
\end{tabular}

FuENTE: AHJ, HB, LESHRSMB, núm. 33-42.

Que si su misión era la de restablecer y cuidar el orden, no debían cometer ningún acto fuera de la legalidad. Por tal motivo envió a todos los comandantes un oficio en el que les recomendaba vigilar estrictamente la disciplina porque algunos destacamentos cometían muchas arbitrariedades en los pueblos, y porque muchos soldados olvidaban el espíritu de su profesión, de las leyes y de su propio honor. También dijo estar enterado de que algunos oficiales toleraban los excesos de la tropa. ${ }^{68}$

Durante los primeros años el número de enfermos por sífilis fue de los más elevados, momento en que se registró el mayor

68 Olveda, De la Insurrección a la Independencia, p. 289. 
porcentaje de ingreso al hospital de milicias locales y foráneas, en su mayoría españoles ${ }^{69}$ A pesar del faltante de información que presenta la fuente entre $1818-1820,{ }^{70}$ después de este periodo la frecuencia de la enfermedad muestra una disminución; durante algunos años se mantiene constante y aun cuando "a partir de 1818 pudo observarse en la intendencia de Guadalajara un descenso de los grupos armados", ${ }^{71}$ la intensidad que presenta el mal en el hospital continúa siendo elevada. Durante más de una década su intensidad rebasó al resto de las enfermedades, incluidas las "fiebres", término que hacía referencia a diversos padecimientos. $^{72}$

69 El registro por calidad deja de anotarse en 1821; hasta este año los datos proporcionan la siguiente información por calidad de los enfermos de gálico: españoles 3 954, mestizos 1 513, indios 405, mulatos 53, negros 33 y 10 registros sin especificar.

70 Durante el periodo de 1818 a 1820 la fuente presenta un faltante absoluto para el caso de la mujer. Si bien el registro de hombres también muestra lagunas, sobre todo entre 1819 y 1820 , el año de 1818 y la serie que va de 1821 a 1823 se encuentran casi completas. De acuerdo con esta información, se puede corroborar, por lo regular, un descenso en el registro de militares ingresados al hospital respecto al número de entradas que este mismo grupo presenta a inicios del periodo de estudio. Véase el cuadro 1.

71 De acuerdo con Olveda, "a partir de 1818 pudo observarse en la intendencia de Guadalajara un descenso de los grupos armados, no sólo por el indulto ofrecido por el gobierno, sino también porque la corona española aplicó mecanismos para reforzar la lealtad”. Olveda, De la Insurrección a la Independencia, p. 367.

72 "El problema médico que más acució a la sociedad española del siglo XvIII fue el que plantearon las fiebres o calenturas, concepto clínico que engloba muy diversos procesos, siempre de aparición frecuente y en bastantes ocasiones de indudable gravedad. La literatura profesional sobre las fiebres atestigua, con su número, la importancia que al tema otorgaron los médicos [...] en la Medicina práctica (1730) de Francisco Sanz de Dios Guadalupe se las describe [...] define el estado febril, analiza con pormenor las calenturas a las que se concede entidad clínica propia, diferenciando las fiebres diarias e intermitentes, la ‘synocho' o fiebre pútrida, la fiebre ardiente y sus variedades y las fiebres hécticas o crónica y la maligna”. GrANJEL, La medicina española del siglo XVIII, pp. 177-178. 
El hecho de que la sífilis representara una enfermedad altamente contagiosa se debió, principalmente, al gran desplazamiento de la población y de ejércitos, porque "las enfermedades venéreas son acompañantes cotidianos de los soldados. La soledad, el distanciamiento de sus parejas y el relajamiento moral y sexual son 'el caldo de cultivo' para el contagio y diseminación de la infección". 73

En términos culturales y sociales, y ante la falta de fuentes documentales ${ }^{74}$ que, para el caso de Guadalajara, ayuden a determinar el impacto que los males venéreos significaron para las autoridades de la ciudad, al parecer, la presencia de estas enfermedades constata el "relajamiento moral". ${ }^{75}$ Sin embargo, desde el campo de la salud pública, la preocupación de las autoridades de Guadalajara no recayó en dar solución a esta problemática. La atención se enfocó en dos puntos: 1) contrarrestar los efectos mortales que epidemias como el tifo de 1814 y la viruela de 1815 causaban en la población; ${ }^{76}$ y 2) atender cuestiones elementales de salud pública y de poca higiene en la ciudad. La reglamentación urbanística y de policía se enfocó en atender problemas relacionados con la limpieza de los espacios públicos, ubicación de cementerios a las afueras de la ciudad, hacinamiento de la población, entre otras ideas de este mismo orden. ${ }^{77}$

El enfoque que demandó la reglamentación, control, regulación y la identificación de las enfermedades venéreas como un grave problema de salud pública, se gesta hasta la segunda

\footnotetext{
73 Márquez, “La sífilis y su carácter endémico,” pp. 1130-1131.

74 Se revisaron diferentes acervos locales en búsqueda de referencias documentales que aportaran mayores datos sobre los enfermos de sífilis, aunque resta mencionar que no se localizó información. Los archivos consultados fueron el ramo de sanidad y algunos años de las actas de cabildo resguardados en el Archivo Municipal de Guadalajara y el ramo de epidemias localizado en la Arquidiócesis de Guadalajara.

75 Márquez, “La sífilis y su carácter endémico,” pp. 1130-1131.

76 Argumaniz, “Las epidemias y las medidas”, pp. 152-167.

77 Argumaniz, “Las epidemias y las medidas”, pp. 297-339.
} 
mitad del siglo xix. A la luz de nuevos saberes médicos y por la influencia que ejercieron las teorías modernas francesas, surgen tratados médicos, códigos sanitarios y diversos reglamentos que norman y controlan la diseminación de la enfermedad y evitan el contagio. ${ }^{78}$

Los efectos prolongados que caracterizaron a este padecimiento se presentaron en la población que ingresó al Hospital de San Miguel. Si bien son contados los casos en que las estancias en el recinto de algunos enfermos de sífilis son amplias (48 convalecientes registraron un encierro de 6 a 24 meses), un aproximado de $61 \%$ se sitúa en un periodo relativo a los 30 días de internamiento, $\mathrm{y}$ al considerar una reclusión hospitalaria que abarque hasta medio año, el total asciende a $88 \%$ de todos los enfermos de gálico. ${ }^{79}$

La mortalidad que presentó la sífilis en el recinto alcanzó 162 defunciones, ${ }^{80}$ estimado que representa $2.26 \%$ respecto a los 7167 registros de ingreso que generó la enfermedad en el Hospital de San Miguel. Este bajo porcentaje de mortalidad de un mal que "a comienzos del siglo xvi era un azote en toda Europa" 11 lleva a plantear algunas consideraciones: en primer lugar, que en el hospital se brindaron y llevaron a la práctica las sanaciones que requerían los enfermos, como la adecuación de algunas salas que se acondicionaron especialmente para atenderlos, tanto a hombres como a mujeres, y se destinaron entre 3 y 4

${ }_{78}$ Márquez, “La sífilis y su carácter endémico,” pp. 1131 y 1132.

${ }^{79} \mathrm{El}$ desglose de los datos relativo al periodo de internamiento hospitalario es el siguiente: hasta 30 días, 4373 registros (61.01\%); hasta medio año, 6 325 registros (88.25\%); entre 6 y 24 meses, 48 registros (0.66\%); y 794 datos $(11.07 \%)$ no especifican la fecha de salida. Debe considerarse que los datos representan aproximaciones y no totales absolutos.

${ }^{80}$ Las 162 defunciones por enfermedades venéreas que registró el Hospital de San Miguel en la década de estudio se dividen en los siguientes grupos de edad: un deceso de una niña de 14 años; entre los 15 a 19 años, dos defunciones; de 20 a 39 años, un total de 115 muertes, y de los 40 años en adelante, 44 decesos. ${ }^{81}$ Laín Entralgo, Historia de la medicina, p. 311. 
espacios para tratarlos con pomadas mercuriales, ácido nítrico, unciones, se les daban baños y diversos remedios terapéuticos que representan las prácticas tradicionales ejercidas en este y otros recintos, con lo cual, posiblemente, mejoraron sus condiciones de salud y por esa razón el porcentaje de mortalidad es bajo; en segundo término, lo más probable es que las 162 defunciones escondan un subregistro que no refleja la gravedad que representaron las enfermedades venéreas; en tercer término, hay que considerar que la sífilis era una enfermedad crónica, situación que lleva a plantear que las defunciones ocurrieron, probablemente, en un periodo "de largo plazo" que rebasa los años de estudio que se plantean en este trabajo. Además, por las limitaciones de información sobre la causa de muerte, así como por la irregularidad de los registros que contiene la misma fuente en los años posteriores, esta situación impide realizar una presentación más allá de lo planteado; y finalmente, la causa de muerte por galio pudo haberse registrado con otros nombres, tal vez como "fiebre", término que representa un "síntoma" de diversos malestares. ${ }^{82}$ Entre las causas de muerte más frecuentes que suscriben los registros del hospital se encuentran las fiebres, con 1193 defunciones, diarrea con 364, heridos con 294, pleuresía con 165 y mal de galio con 162 .

No es fortuito que los párrocos de los cinco curatos de Guadalajara registren durante este mismo periodo de estudio "muy pocos decesos" 83 de un mal venéreo cuyo $40 \%$ de enfermos hospitalizados (2899 ingresos) se registraron como originarios de Guadalajara y como feligreses de sus mismas parroquias. De acuerdo con Argumaniz, durante esta época los registros parroquiales de defunción de los curatos de Guadalajara consignan la causa de muerte en algunos años. En los datos proporcionados

82 Granjel, La medicina española del siglo XVIII, pp. 177-178.

83 Argumaniz registra en las parroquias de Guadalajara "contados casos" de mortalidad por galio. Argumaniz, "Las epidemias y las medidas", pp. 211-218. 
por el autor sobresale el término "fiebre" para referirse al deceso de la población durante el tifo de $1814 .{ }^{84}$ Probablemente, la mortalidad por sífilis no se dio a conocer ni se registró en las defunciones como tal, al menos en las del hospital, para no dimensionar ni dar a conocer un grave problema de salud pública en las normas culturales y prácticas sexuales de una sociedad católica como la tapatía de fines de la colonia. No olvidemos el contexto de la segunda década del siglo XIX con la presencia constante de cruentos periodos de sobremortalidad (tifo de 1814 y viruela de 1815) y la problemática que significó el periodo de insurgencia: "las epidemias reconocidas como causantes de grandes mortandades eran la preocupación fundamental de las autoridades sanitarias, mientras la sífilis no era identificada como enfermedad endémica y permanecía en la secrecía. Las enfermedades venéreas, dado su carácter de trasmisión sexual, son mantenidas en secreto a causa de la vergüenza". ${ }^{85} \mathrm{Al}$ parecer, esta misma situación se presentó en Guadalajara, y se confirmó en los registros de la fuente hospitalaria y en la parroquial.

Los enfermos de galio se distribuyeron entre espacios para hombres, mujeres y militares.

Lo que interesa resaltar son las variaciones que presentó la enfermedad año tras año en su distribución por espacios y la lógica del internamiento. Para los hombres sobresale la cobertura de Espíritu Santo con 55\% de los ingresos y para las mujeres Corazón de Jesús con 91\%. Si bien la "Nueva Fábrica de Belén", construida en 1794, destinó tres espacios de mediana capacidad (San Jerónimo para gálicos, y San Francisco de Paula y Los Dolores para las unciones), que registran $6.5 \%$ de los convalecientes, ante la gran cantidad de enfermos y la gravedad del problema, se debieron acondicionar al menos tres salas, dos de

84 Argumaniz, “Las epidemias y las medidas”, p. 214.

85 Márquez, “La sífilis y su carácter endémico”, p. 1107. 


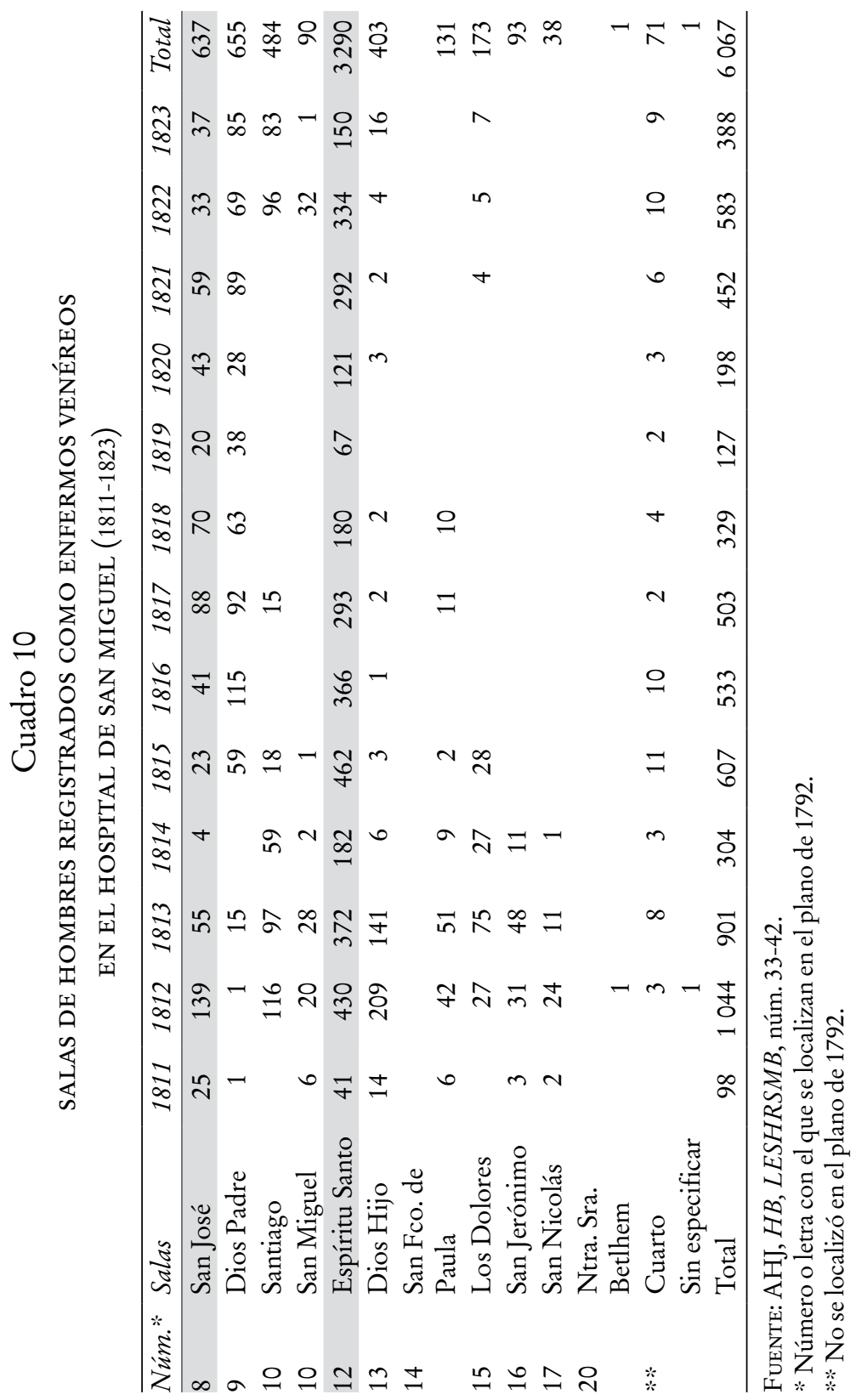




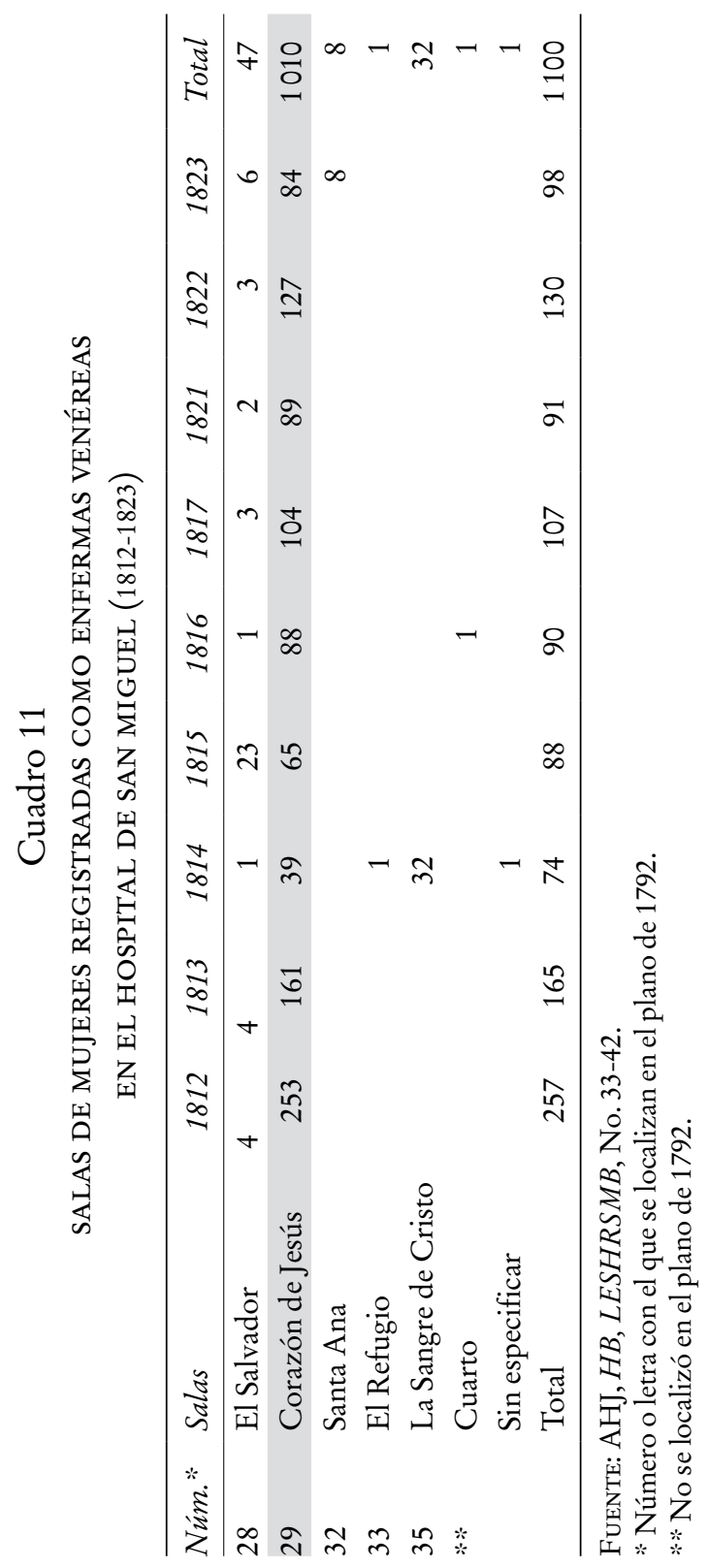


ellas de las más grandes del hospital (una de hombres y otra de mujeres), con rango de $60 \%$ entre ambas.

El estudio de este problema resulta trascendental para analizar la enfermedad en un entorno hospitalario. No es fortuito que los espacios asignados a los gálicos formen parte de las "salas de cirugía”. De acuerdo con la visita que se realizó al Hospital de San Miguel en marzo de 1814, el personal que las atendía se relacionaba con el ejercicio de ese mismo saber:

A mas de estos dos facultativos [José de Herrera y el practicante mayor] tienen las salas de cirugía otros once practicantes, y catorce sirvientes inferiores, distribuidos estos últimos en la forma siguiente: en el departamento de paysanos heridos un enfermero, un cataplasmero, y tres para la limpieza; y en el de la tropa un enfermero, un untador de unturas comunes, uno que hace lo mismo con el mercurio, uno que aplica fomentos, uno que pone cataplasmas, uno que da los baños, y tres destinados a la limpieza. Cuatro o cinco de estos sirvientes deverian escusarse obligando a que hiciesen sus oficios los practicantes, siempre que no se tenga por conveniente disminuir el numero de estos, que tambien parece superabundante. ${ }^{86}$

Las salas de cirugía fueron atendidas por 27 personas: el cirujano José Herrera, los practicantes mayores, menores y sirvientes. Considerando que el galio representó la enfermedad con mayor número de ingresos, el personal era reducido, aunque es evidente que el resto de malestares también demandó atención.

Espíritu Santo (núm. 12) correspondió al "departamento de la tropa” y consignó $89 \%$ (2929 registros) de militares que padecieron algún mal venéreo. Esta sala tenía más cercano el servicio de baños (núm. 26) para que pudieran bañarse los que lo necesitaran; dentro de los saberes del entorno, el baño representó un remedio terapéutico para su sanación. San Francisco

86 AHAG, $O A, H B$, c. 4, S/N (marzo 1814) f. 13v.-14fr. 
de Paula y Los Dolores debieron destinarse para las unciones. Los cuartos, por lo regular, consignan a militares de alto rango (tenientes, subtenientes, sargentos) o personas "distinguidas", como fue el español don Mariano Ibarra y otros más; el resto de los espacios debieron acondicionarse para resguardar a la gran cantidad de enfermos y, para el caso de mujeres, Corazón de Jesús (núm. 29) se destinó para atender el mismo padecimiento y también dispusieron del servicio de baños para sus sanaciones (núm. 25), pero, a diferencia del caso de los hombres, esta sala no las comunicaba directamente con ese cuarto.

Se dispuso de ocho practicantes designados para los fomentos, cataplasmas, ungüentos, las unturas comunes, pomadas mercuriales, de ácido nítrico y baños, aplicados como parte de los remedios terapéuticos y que representan las prácticas tradicionales ejercidas en otros recintos. Por ejemplo, en 1800 en el Hospital de San Andrés de la ciudad de México se introdujo un tratamiento basado en ácido nítrico que formaba parte de los tratamientos más novedosos y actuales aplicados a los gálicos. ${ }^{87}$ Para el caso del Hospital de San Miguel, este componente formó parte de los medicamentos registrados en la botica del recinto..$^{88}$

Rodríguez-Sala proporciona un informe de 1791 en donde señala los remedios que en el Hospital de San Andrés fueron aplicados a cuatro regimientos militares. ${ }^{89}$ En el "Informe sobre los resultados obtenidos para curar el mal venéreo en las tropas con el método de Viana [...]" se detallan los síntomas, remedios (número de purgas, baños, sudores y lavativas), la duración de la curación, sus efectos y resultados, aplicados a un aproximado de 80 soldados de tres regimientos. A pesar de que un porcentaje

87 Morales Cosme, El Hospital General de San Andrés, p. 102.

88 "Lista de los medicamentos que faltan en la botica" del Hospital de San Miguel de Belén. AHAG, $O A, H B$, c. 4, S/N (marzo 1814) f. 23 fr.-24v.

${ }^{89}$ Rodríguez-SAla, Los cirujanos del ejército en la Nueva España, apéndice VI: "Informe sobre los resultados obtenidos para curar el mal venéreo en las tropas con el método de Viana en el Hospital de San Andrés", pp. 381-384. 
reducido de militares "salió bueno" del recinto de San Andrés, la mayoría lo hizo en las malas condiciones en que habían ingresado; varios salieron con dolores generales y hubo quien "se fingió bueno por huir de los ladrillos calientes con que dan los vapores porque lo quemaban"..$^{0}$

Una certificación médica elaborada en 1796 por don Ignacio Lucero, cirujano de la Real Cárcel de la Ciudad de México, detalla algunas de las características que presentó un enfermo de galio, el reo don Francisco Lozada. El facultativo señaló:

Haviendolo verificado con toda exactitud, estando en este oficio mi cargo dijo, que de los dolores articulares de las extremidades inferiores no hay duda de la causa el dilatado tiempo de el contacto de los grillos, y asi mismo, el mal uso de los alimentos y la mala disposición en su naturaleza, pues por esto ha contraido el paciente don francisco la enfermedad nombrada sifilitica, como también algunas ulceras en el balano y supresión de gonorrea [...] Lo que se halla son vestigios de galico, asi por las cicatrices, que le vio en la boca, como por las escoriaciones del viril, añadiendo a esto que se queja de muchos dolores nocturnos; todo lo cual dice esta contagiado de galico. ${ }^{91}$

Pese a que el informe no corresponde a un convaleciente atendido en el Hospital de San Miguel, la referencia ilustra algunas de las características más representativas de la enfermedad, sus síntomas, remedios para la sanación (unciones mercuriales, fomentos, baños, etc.) y se deja entrever el "obrar de manos" del cirujano, a quien correspondió atenderlo. Situación que también se corroboró en el recinto de San Miguel; su atención se brindó

90 Rodríguez-Sala, Los cirujanos del ejército en la Nueva España, apéndice VI: "Informe sobre los resultados obtenidos para curar el mal venéreo en las tropas con el método de Viana en el Hospital de San Andrés”, pp. 381-384. 91 AGN, IV / c. 2534 / 7613 / 23, 74 fs. Expediente sobre la enfermedad de don Francisco Lozada, f. 51fr. y 54v. 
en salas de cirugía teniendo como encargados a los practicantes de ese mismo saber.

Este orden terapéutico que presentaron algunas salas, de igual forma se constata en el análisis de los nueve padecimientos más representativos que le siguen al galio. De acuerdo con la distribución que muestran en su conjunto las diez enfermedades más frecuentes, tenemos lo siguiente (véanse los cuadros 12 y 13 ).

Aunque los enfermos se distribuyen a lo largo de los espacios, tanto de hombres como de mujeres, este no ocurre con la misma proporción. No es fortuito que ciertos convalecientes ocupen mayores espacios en determinadas salas. Si observamos la dinámica de hombres en San José, Santiago y Espíritu Santo y mujeres en Corazón de Jesús (cuadro 12), muestran mayores ingresos con padecimientos que se manifiestan "por de fuera del cuerpo humano", ${ }^{92}$ malestares externos relacionados con el ejercicio de la cirugía: el caso del galio, contusos, los que padecen algún tumor, los sarnosos y los heridos, estos últimos, tienen mayor ocupación en Dios Padre porque se designó para "reos", es decir, heridos que estaban involucrados en un proceso judicial, por eso los mantenían aparte. En cambio, San Miguel y Dios Hijo para hombres y El Salvador para mujeres (cuadro 13), constatan el mismo fenómeno con causas que hacen

92 En el Florilegio medicinal, Esteyneffer se refiere a dos tipos de causas en que se manifiestan las enfermedades en el cuerpo humano: "causas extrínsecas" (externas) y “causas intrínsecas” (internas). Respecto a las primeras, señala: "Prosiguiendo de las causas susodichas, de ellas ay unas, que se llaman Extrinsecas, porque se ofrezen por de fuera del Cuerpo humano, al que alteran, y varian sus dolencias, como son: el Aire; la Comida, y Bebida; el Sueño, y Desvelo; el Movimiento, o Exercicio, y Quietud, la Evaquacion, y repleción; los Accidentes, o Pasiones del ánimo. Todos estos casi necesario se ofrecen al Cuerpo humano, los quales, asi como siendo con medida, y proporción, conservan el Cuerpo con salud, asi también, faltando, o excediendo su proporción, o medida, ocasionan las Enfermedades; y estas causas dichas son las ordinarias, fuera de otras que casualmente se suelen ofrecer”. EsTEYNEFFER, Florilegio medicinal, p. 3. 
Cuadro 12

DISTRIBUCIÓN POR SALA Y ENFERMEDAD DE LOS PADECIMIENTOS RELACIONADOS CON EL EJERCICIO DE LA CIRUGÍA CON MAYORES REGISTROS EN EL HOSPITAL DE SAN MIGUEL (1811-1823)

\begin{tabular}{|c|c|c|c|c|c|c|c|}
\hline Sexo & Núm.* & Salas & Gálico & Herido & Tumor & $\begin{array}{c}\text { Contu- } \\
\text { sión }\end{array}$ & Sarna \\
\hline $\mathrm{H}$ & 8 & San José & 637 & 294 & 63 & 54 & 18 \\
\hline $\mathrm{H}$ & 9 & Dios Padre & 655 & 2171 & 73 & 178 & 63 \\
\hline $\mathrm{H}$ & 10 & Santiago & 484 & 270 & 56 & 36 & 4 \\
\hline $\mathrm{H}$ & 10 & San Miguel & 90 & 29 & 8 & 6 & 1 \\
\hline $\mathrm{H}$ & 12 & Espíritu Santo & 3290 & 702 & 156 & 186 & 136 \\
\hline $\mathrm{H}$ & 13 & Dios Hijo & 403 & 170 & 41 & 12 & 10 \\
\hline $\mathrm{H}$ & 14 & San Fco. de Paula & 131 & 67 & 12 & 3 & 0 \\
\hline $\mathrm{H}$ & 15 & Los Dolores & 173 & 500 & 11 & 14 & 1 \\
\hline $\mathrm{H}$ & 16 & San Jerónimo & 93 & 32 & 4 & 1 & 2 \\
\hline $\mathrm{H}$ & 17 & San Nicolás & 38 & 45 & 3 & 1 & 0 \\
\hline $\mathrm{H}$ & & Otras salas & 73 & 13 & 5 & 5 & 3 \\
\hline M & 28 & El Salvador & 47 & 34 & 4 & 1 & 10 \\
\hline M & 29 & Corazón de Jesús & 1010 & 589 & 157 & 68 & 58 \\
\hline \multirow[t]{2}{*}{ M } & & Otras salas & 43 & 16 & 5 & 5 & 0 \\
\hline & & Total & 7167 & 4932 & 598 & 570 & 306 \\
\hline
\end{tabular}

FuENTE: AHJ, $H B, L E S H R S M B$, núm. 33-42;

* Número o letra con el que se localizan en el plano de 1792.

"enfermar interiormente el cuerpo", ${ }^{93}$ malestares asociados con el ejercicio de la medicina: fiebre, pleuresía, reumatismo, diarrea e hidropesía.

En el caso de los enfermos de "fiebres", que representan el $25 \%$ de los ingresos, fueron distribuidos en espacios distintos

93 "Otras Causas ay Intrinsecas, que son los humores interiores complexionales, los quales hazen enfermar interiormente el cuerpo, y todas sus partes." EsteynefFer, Florilegio medicinal, p. 3. 


\section{Cuadro 13}

DISTRIBUCIÓN POR SALA Y ENFERMEDAD DE LOS

PADECIMIENTOS RELACIONADOS CON EL EJERCICIO

DE LA MEDICINA CON MAYORES REGISTROS EN EL HOSPITAL DE SAN MIGUEL (1811-1823)

\begin{tabular}{lllccccc}
\hline & & & & Pleure- & & Reuma- & Hidro- \\
Sexo & Núm.* & Salas & Fiebre & sía & Diarrea & tismo & pesía \\
\hline $\mathrm{H}$ & 8 & San José & 5 & 3 & 3 & 8 & 2 \\
$\mathrm{H}$ & 9 & Dios Padre & 1251 & 220 & 143 & 208 & 50 \\
$\mathrm{H}$ & 10 & Santiago & 6 & 0 & 1 & 6 & 0 \\
$\mathrm{H}$ & 10 & San Miguel & 524 & 30 & 24 & 34 & 10 \\
$\mathrm{H}$ & 12 & Espíritu Santo & 22 & 3 & 1 & 25 & 2 \\
$\mathrm{H}$ & 13 & Dios Hijo & 2540 & 626 & 327 & 305 & 114 \\
$\mathrm{H}$ & 14 & San Fco. de Paula & 64 & 3 & 14 & 11 & 8 \\
$\mathrm{H}$ & 15 & Los Dolores & 567 & 139 & 53 & 39 & 8 \\
$\mathrm{H}$ & 16 & San Jerónimo & 108 & 3 & 0 & 4 & 0 \\
$\mathrm{H}$ & 17 & San Nicolás & 207 & 17 & 7 & 20 & 2 \\
$\mathrm{H}$ & & Otras salas & 29 & 2 & 7 & 13 & 3 \\
$\mathrm{M}$ & 28 & El Salvador & 1474 & 411 & 402 & 122 & 169 \\
M & 29 & Corazón de Jesús & 19 & 2 & 8 & 3 & 9 \\
M & & Otras salas & 231 & 2 & 9 & 3 & 0 \\
& & Total & 7047 & 1461 & 999 & 801 & 377 \\
\hline
\end{tabular}

FueNTE: AHJ, HB, LESHRSMB, núm. 33-42;

* Número o letra con el que se localizan en el plano de 1792.

a los sifilíticos, que presentan mayor ocupación. Para el caso de los varones, resaltan Dios Hijo con $48 \%$ y Dios Padre con $23 \%$, aunque en esta última la situación fue diferente. Si bien, entre 1812-1814 resguardó a enfermos de fiebre, después de 1815 funcionó como una sala de "reos" que presentaban este y otros padecimientos.

De acuerdo con el plano núm. 1, Dios Hijo (núm. 13) se destinó para atender este mal. Este casi 50\% de internamiento denota la aplicación de mecanismos que rigieron el funcionamiento 
interno de algunas áreas del hospital, en este caso, debido a la fiebre y su carácter infectocontagioso que la representaba, mismo que era desconocido por los empleados del hospital. En mujeres la atención se concentra en El Salvador (núm. 28), con $85 \%$ de los ingresos; aun cuando no fue concebido por el plano de 1792 como una de las piezas destinadas para ese mal, se adaptó a la problemática del momento.

Doce son los enfermeros que asisten en el Departamento de Medicina; pero de estos uno solo es el destinado a velar de noche sobre las enfermerías, lo que es imposible desempeñe con la exactitud correspondiente a tanto numero de enfermos, $y$ asi se hace preciso que se reparta este cuidado entre cuatro o seis, que turnando entre si velen, y ronden todas las salas ministrando a los enfermos los auxilios que necesiten; y que esta providencia sea extensiva al Departamento de Mujeres, por ser también una sola enfermera la que tiene este oficio, con el misero premio de veinte reales mensuales. ${ }^{94}$

El servicio brindado por los facultativos en el Departamento de Medicina, presentó inconsistencias y el personal era escaso para atender las necesidades diarias; solo 12 enfermeros lo atendían y una trabajadora era destinada para el área de mujeres. No puede dejarse de lado el desmesurado porcentaje de convalecientes que por diversos malestares sobresaturaron estas y otras áreas que, de igual manera, requerían atención.

La distribución de los enfermos de fiebre se hizo en espacios diferentes respecto a los que en este mismo momento tuvieron mayor demanda: los gálicos. A pesar de esta vecindad que presentan ambos padecimiento, se constata una organización terapéutica y sobresalen algunos mecanismos que rigen el funcionamiento del hospital: para las fiebres, en hombres, el ingreso se registró en espacios concebidos para ese mal, principalmente

94 AHAG, $O A, H B$, c. 4, S/N (marzo 1814), f. $13 \mathrm{fr}$. 
en Dios Hijo con casi 50\%, a cargo del médico del hospital, Mariano de la Torre, y de los practicantes que ejercían en esa misma rama, mientras que para las mujeres con el mismo malestar, el internamiento se hizo en El Salvador con 85\%; en los sifilíticos hombres se destinó Espíritu Santo, que registró $54 \%$, a cargo del cirujano José Herrera y de los practicantes del mismo saber, y Corazón de Jesús alcanzó 91\% de mujeres. Estas áreas representan cuatro de los espacios más grandes del hospital y son de los más importantes que atendían los facultativos y sus ayudantes, pero de forma separada.

Este funcionamiento ${ }^{95}$ se estableció en un reglamento del recinto fechado en 1797, en donde los facultativos tienen una presencia importante:

$22^{\circ}$. A cualquiera hora del dia o de la noche deben admitirse en el Hospital los pobres enfermos que ocurran, y en el acto, según sus males han de destinarse a las salas de Medicina o Cirugía, y socorrer por el Practicante su necesidad en términos que por falta de pronta asistencia, no experimente se agrabe la enfermedad. Si ella fuere de calidad que exija el auxilio pronto del Médico o Cirujano, no se escusara llamar a qualquiera de los dos sin pararse en la incomodidad de la hora. ${ }^{96}$

Finalmente, mencionar que esta separación entre "salas de medicina" y "salas de cirugía" responde a la división y diferenciación social que existió entre los saberes y el ejercicio que

${ }_{95}$ De acuerdo con Oliver Sánchez, "a lo largo del siglo xvir las salas del hospital de Belén estuvieron divididas en función de tres criterios: la separación por sexos; por razones étnicas, aunque solo funcionó con los hombres, donde había una sala especial para atender a los españoles, y la separación entre 'enfermos de cirugía' y 'enfermos de medicina', que correspondía a la división que existía entonces entre estas dos prácticas”. Oliver, Los betlemitas y la construcción, p. 31.

96 AMG, S, 7.2 / 1797, Ant. Paq. 14, leg. 47. Instrucción, 13 fojas (24 de agosto de 1797). 
practicaban los facultativos que las tenían a su cargo: médico y cirujano. El primero por haberse graduado en la universidad tenía más prestigio social que el otro, este último por ejercer un arte manual era menospreciado. ${ }^{97}$ Los médicos indicaban el tratamiento que consideraban conveniente, platicaban con el enfermo y lo observaban, nunca lo tocaban. Cuando se intervenía físicamente algún padecimiento participaban los cirujanos, los barberos, ${ }^{98}$ los flebotomianos o sangradores, ${ }^{99}$ los algebristas, ${ }^{100}$ los boticarios y los practicantes de cirugía. Estos realizaban las operaciones quirúrgicas, extirpaban tumores, amputaban extremidades, corregían fracturas, extraían proyectiles de las heridas, ligaban arterias, suturaban descalabros, se encargaban de lesiones delicadas, practicaban autopsias ${ }^{101}$ y atendían a los enfermos de galio.

\section{CONCLUSIONES}

La presencia de enfermedades que presentan una sintomatología asociada con malestares infectocontagiosos de las vías respiratorias y gastrointestinales (fiebres, diarrea, pleuresía, etc.), por lesiones, heridas y, sobre todo, por resultas de conductas sexuales (gálicos), aunada a los estragos causados por los periodos de sobremortalidad de tifo de 1814 y de viruela de $1815,{ }^{102}$ constatan los graves problemas endémicos y epidémicos que en

\footnotetext{
97 Márquez, La desigualdad ante la muerte, p. 139.

${ }_{98}$ El que tiene por oficio afeitar o hacer la barba. También se les llamaba así a los sangradores, pues los barberos solían ejercer este oficio. Enciclopedia Universal, vol. vII, p. 682.

99 Los flebotomianos eran los cirujanos que practicaban la operación de la sangría; también algunos se dedicaban a sacar muelas. CAstells, Diccionario de medicina, vol. II, p. 38.

${ }^{100}$ Los algebristas eran quienes acomodaban los huesos dislocados. CASTELLS, Diccionario de medicina, vol. I, p. 139.

101 Huerta, "La cirugía y sus instrumentos", p. 99.

102 Argumaniz, "Las epidemias y las medidas”, pp. 152-167.
} 
salud pública padeció la ciudad y su población en el contexto de la independencia.

En el caso específico de las enfermedades infecciosas de trasmisión sexual (gálicos), el hecho de que represente la primera enfermedad del hospital con una cuarta parte de todos los registros de ingreso, se debió en gran medida a las tropas militares que padecieron este mal. Este grupo social, al parecer, la diseminó entre la población tapatía y la mantuvo en forma endémica. No es fortuito que durante el periodo de independencia, $55 \%$ de todos los enfermos de sífilis correspondan a militares, en su mayoría españoles. Un malestar que culturalmente se les ha atribuido por su calidad de viajeros y por mantenerse distantes de la familia. ${ }^{103}$ Esto provocó conductas sociales con riesgo de contagio por enfermedades sexuales. Fue tal la situación que la sala Espíritu Santo funcionó como el "departamento de la tropa" sifilítica del hospital. Al considerar el estimado en general, el porcentaje dimensiona una falta grave en las normas culturales y sexuales de los tapatíos, ya que un aproximado de 40\% (2899 registros) de todos los enfermos de galio eran originarios de Guadalajara. Son datos que descubren la presencia de la sífilis no solo en militares jóvenes, sino en todos los grupos sociales y de distintas edades de la población. Los niños no se salvaron de padecer este mal. Si consideramos el registro de la calidad, que deja de anotarse en 1821, hasta ese año, los españoles representan el grueso de los enfermos con $66 \%$, mientras que a los mestizos, indios, etc., les corresponde una proporción menor.

Con el resto de las enfermedades consignadas en los libros de ingresos al hospital, el estudio de este fenómeno es diferente. La gran estimación que presentaron los malestares cotidianos infectocontagiosos de las vías respiratorias y gastrointestinales resultó lógica, padecimientos comunes que a diario aquejaban a la población civil y militar. No olvidemos que durante este

103 Márquez, “La sífilis y su carácter endémico,” pp. 1130-1131. 
periodo se presentaron las epidemias de tifo y de viruela cuyas consecuencias se vieron manifestadas en cruentos periodos de sobremortalidad. ${ }^{104}$ Esta situación recrudeció aún más la presencia de la sífilis en Guadalajara, grave problema endémico de salud pública que padeció la población tapatía en el marco de la independencia y que, de acuerdo con el número de defunciones registradas (162 decesos), al parecer, su impacto mortal se mantuvo en la secrecía o incluso, plantear la posibilidad de que la mortalidad de esta enfermedad crónica pudo registrarse en los años posteriores al periodo de estudio que abarca este trabajo.

A pesar de que estos problemas de enfermedad se vieron reflejados en los ingresos que presentó el Hospital de San Miguel al sobresaturarlo con todo tipo de malestares, el recinto dimensionó una organización terapéutica entre sus salas. El internamiento que en espacios separados presentaron, por lo común, la mayoría de enfermos de galio con poco más de $25 \%$ de los ingresos, aunado al resto de malestares consignados en los cuadros 12 y 13 , con un promedio de $60 \%$, alcanza un aproximado de $85 \%$ de todos los ingresos y presentó orden en la función hospitalaria. Esta situación trasluce algunos de los criterios establecidos desde la construcción en 1794 de la "Nueva Fábrica de Belén". Si bien, "la distribución dada a las salas tuvo como eje principal las enfermedades epidémicas", ${ }^{105}$ como fue el caso de los virulentos de 1797-1798 atendidos de forma separada en Dios Padre y La Pasión, ${ }^{106}$ con el resto de padecimientos consignados en el presente estudio se observa una organización del hospital entre males asociados al ejercicio de la medicina y de la cirugía.

Finalmente, considerar que los lineamientos que rigieron al recinto deben ser vistos y valorados a luz del movimiento

104 Argumaniz, “Las epidemias y las medidas,” pp. 152-167.

105 Oliver, El Hospital Real, p. 262.

$106 \mathrm{El} 74.31 \%$ de virulentos se atendieron en estas dos salas. SALAs, "El funcionamiento y la dinámica interna”, p. 88. 
insurgente de 1810. Lucha armada que significó el arribo a la ciudad de militares enfermos que necesitaban ingresar al hospital, aunado al resto de la población que demandaba el mismo servicio. Esta situación requirió de los recursos económicos disponibles, lo que para el hospital significó déficit en sus finanzas y carencia de personal. Este fenómeno, que propició el movimiento armado, sin duda trastocó los diferentes rubros que conformaban la administración y finanzas no solo locales, sino las de la misma corona española que, para este momento, se inmiscuyó en diferentes enfrentamientos bélicos con potencias europeas. Esta situación, sin duda, terminó por afectar a los diferentes organismos que dependían de los recursos que la corona erogaba; el caso del Hospital de San Miguel no fue la excepción. En este entorno de guerra, epidemias y enfermedades venéreas, debemos valorar el funcionamiento del recinto que, a pesar de las deficiencias que presentó, deja ver el proceso que significó la asistencia y función hospitalaria en Guadalajara.

\section{SIGLAS Y REFERENCIAS}

AGN, IV Archivo General de la Nación, fondo Indiferente Virreinal, Ciudad de México, México.

AHAG, $O A, H B$ Archivo Histórico de la Arquidiócesis de Guadalajara, fondo Obras Asistenciales, sección Hospital de Belén, Guadalajara, Jalisco, México.

AHJ, HB, LESHRSMB y $M$ Archivo Histórico de Jalisco, fondo Hospital de Belén, sección Libros de entradas y salidas del Hospital Real de San Miguel de Belén y fondo Mapoteca, Guadalajara, Jalisco, México.

AMG, $S$ Archivo Municipal de Guadalajara, fondo Sanidad, Guadalajara, Jalisco, México.

BPEJ, CM Biblioteca Pública del Estado de Jalisco, fondo Colección de Manuscritos, Guadalajara, Jalisco, México.

Anderson, Rodney, Guadalajara a la consumación de la Independencia: estudio de su población según los padrones de 1821-1822, Guadalajara, Jalisco, México, Gobierno de Jalisco, Unidad Editorial, 1983. 
Alberro, Solange, "La sexualidad manipulada en Nueva España: modalidades de recuperación y de adaptación frente a los tribunales eclesiásticos", en $\mathrm{Fa}$ milia y sexualidad en Nueva España, México, Fondo de Cultura Económica, 1982, pp. 238-257.

Argumaniz Tello, Juan Luis, “Las epidemias y las medidas implementadas por las autoridades en Guadalajara, 1762-1825”, tesis de doctorado en ciencias sociales, Guadalajara, Jalisco, México, Universidad de Guadalajara, 2019.

Becerra, Celina Guadalupe y Alejandro Solís Matías, La multiplicación de los tapatíos 1821-1921, México, El Colegio de Jalisco, H. Ayuntamiento de Guadalajara, 1994.

Becerra, Celina Guadalupe (comp.), Los occidentes de México (siglos XVIXIX) El archivo: instrumento y vida de la investigación histórica, Guadalajara, Jalisco, México, Universidad de Guadalajara, 1997.

Castells, José, Diccionario de medicina, cirugía, farmacia, medicina legal, física, química, botánica, mineralogía, zoología y veterinaria, París, Librería de Rosa y Bouret, 1860.

De la Mota y Escobar, Alonso, Descripción geográfica de los Reinos de Nueva Galicia, Nueva Vizcaya y Nuevo León, Guadalajara, Jal., Instituto Jalisciense de Antropología e Historia, Colección de Obras Facsimilares I, 1966.

Enciclopedia Universal Ilustrada Europeo Americana, Madrid, Barcelona, Espasa Calpe, Editores, 1910, vol. viI.

EsteynefFer, Juan de, Florilegio medicinal de todas las enfermedades, sacado de varios, $y$ clasicos authores, para bien de los pobres, $y$ de los que tienen falta de medicina, en particular para las Provincias Remotas, en donde administran los RR PP Misioneros de la Compañía de Jesús, México por los Herederos de Juan Joseph Guillena Carrascoso, en el Empedradillo, 1712.

Familia y sexualidad en Nueva España. Memoria del Primer Simposio de Historia de las Mentalidades: "Familia, matrimonio y sexualidad en Nueva España”, México, Fondo de Cultura Económica, 1982.

Foucault, Michel, Historia de la locura en la época clásica, México, Fondo de Cultura Económica, t. I, 1999. 
Gálvez Ruız, María Ángeles, La conciencia regional en Guadalajara y el gobierno de los intendentes (1786-1800), México, Unidad Editorial del Gobierno de Jalisco, 1996.

Gispert, Carlos (dir.), Diccionario de Medicina, Barcelona, España, Oceano Mosby.

Granjel, Luis S., La medicina española del siglo XVIII, Salamanca, España, Ediciones Universidad de Salamanca, 1979.

Huerta Jaramillo, Ana María Dolores, "La cirugía y sus instrumentos en el Real Hospital de San Pedro de Puebla. 1796-1826”, en Rodríguez de Romo y Martínez Barbosa (coords.), 2001, pp. 99-111.

Laín Entralgo, Pedro, Historia de la medicina, Barcelona, España, Salvat Editores, 1978.

MÁrquez Morfín, Lourdes, La desigualdad ante la muerte en la cindad de México. El tifo y el cólera, México, Siglo Veintiuno Editores, 1994.

Márquez Morfín, Lourdes, "La sífilis y su carácter endémico en la ciudad de México”, en Historia Mexicana, LXIv: 3 (255) (ene.-mar. 2015), pp. 1099-1161.

Méndez Fausto, Isabel Eugenia, El núcleo médico funerario del Hospital Civil, siglos XVIII y XIX, Guadalajara, Jalisco, México, Universidad de Guadalajara, Centro Universitario de Arte, Arquitectura y Diseño, 2009.

Menéndez Valdés, José, Descripción y censo general de la Intendencia de Guadalajara, 1789-1793, estudio preliminar de R. María Serrera, Guadalajara, Jalisco, México, Unidad Editorial, 1980.

Morales Cosme, Alba Dolores, El Hospital General de San Andrés. La modernización de la medicina novohispana (1770-1833), Patricia Aceves Pastrana (ed. y coord.), México, Universidad Autónoma Metropolitana, 2002.

Muriel, Josefina, Hospitales de la Nueva España, t. I Fundaciones del siglo XVI, México, Universidad Nacional Autónoma de México, Cruz Roja Mexicana, 1990.

Oliver Sánchez, Lilia, El Hospital Real de San Miguel de Belén, 1581-1802, México, Universidad de Guadalajara, 1992. 
Oliver Sánchez, Lilia, "Mortalidad y los registros hospitalarios en Guadalajara durante el siglo xviı”, en BECERRA (comp.), 1997, pp. 453-466.

Oliver SÁnchez, Lilia, "La importancia de los registros hospitalarios para el análisis de la epidemia y escasez de alimentos en Guadalajara, 1785-1786”, en Letras Históricas, 2: 3 (otoño-invierno 2010), pp. 47-67.

Oliver SÁnchez, Lilia, Los betlemitas y la construcción de la nueva "fábrica" para el Hospital Real de San Miguel de Belén, Guadalajara 1787-1794, Guadalajara, Jalisco, México, Universidad de Guadalajara, 1992.

Oliver SÁnchez, Lilia, Salud, desarrollo urbano y modernización en Guadalajara [1797-1908], Guadalajara, Jalisco, México, Universidad de Guadalajara, 2003.

OlvedA, Jaime, De la Insurrección a la Independencia. La guerra en la región de Guadalajara, Zapopan, Jalisco, El Colegio de Jalisco, 2011.

Ramos Escobedo, Alejandro, El manicomio del Hospital Real de San Miguel de Belén de Guadalajara, 1794-1905, Guadalajara, Jalisco, México, Universidad de Guadalajara, Centro Universitario de Ciencias de la Salud, 2005.

Rodríguez de Romo, Ana Cecilia y Xóchitl Martínez Barbosa (coords.), Estudios de historia de la medicina: abordajes e interpretaciones, México, Universidad Nacional Autónoma de México, 2001.

Rodríguez-Sala, María Luisa, Los cirujanos del ejército en la Nueva España (1713-1820), ¿miembros de un estamento profesional o una comunidad científica?, México, Universidad Nacional Autónoma de México, 2005.

Rojas Galván, José, Las milicias de Nueva Galicia. Élite, indígenas y castas. Los soldados del rey (1758-1810), México, Instituto Nacional de Antropología e Historia Jalisco, Consejo Nacional para la Cultura y las Artes, 2009.

Salas Pelayo, Hugo Humberto, "El funcionamiento y la dinámica interna de las salas de enfermos del Hospital Real de San Miguel de Belén de Guadalajara, 1797-1799”, en Letras Históricas, 9: 18 (primavera-verano 2018), pp. 63-92.

Seis impresos relativos al establecimiento y gobierno de diversos hospitales navales españoles del siglo XVIII (1748-1781), México, Rolston-Bain, 1983. 
SERRERA, Ramón María, Guadalajara ganadera. Estudio regional novohispano (1760-1805), México, El Colegio de San Luis, Universidad Autónoma de Aguascalientes, 2015.

VAN Young, Eric, La ciudad y el campo en el México del siglo XVIII. La economía rural de la región de Guadalajara, 1675-1820, México, Fondo de Cultura Económica, 1989. 